\title{
The Skin Interactome: A Holistic "Genome- Microbiome-Exposome" Approach to Understand and Modulate Skin Health and Aging
}

This article was published in the following Dove Press journal: Clinical, Cosmetic and Investigational Dermatology

\author{
la Khmaladze (D) \\ Michele Leonardi (D) \\ Susanne Fabre' \\ Cyril Messaraa $\mathbb{D}^{2}$ \\ Alain Mavon' \\ 'Skin Research Institute, Oriflame \\ Cosmetics AB, Stockholm, Sweden; \\ ${ }^{2}$ Research and Development, Oriflame \\ Cosmetics Ltd, Bray, Ireland
}

Correspondence: Alain Mavon Senior Director Scientific Research \& Innovation, Skin Research Institute, Oriflame Cosmetics AB, Mäster Samuelsgatan 56, Stockholm III 2I, Sweden

Email alain.mavon@oriflame.com

\begin{abstract}
Higher demands on skin care cosmetic products for strong performance drive intense research to understand the mechanisms of skin aging and design strategies to improve overall skin health. Today we know that our needs and influencers of skin health and skin aging change throughout our life journey due to both extrinsic factors, such as environmental factors and lifestyle factors, as well as our intrinsic factors. Furthermore, we need to consider our microflora, a collection of micro-organisms such as bacteria, viruses, and fungi, which is a living ecosystem in our gut and on our skin, that can have a major impact on our health. Here, we are viewing a holistic approach to understand the collective effect of the key influencers of skin health and skin aging both reviewing how each of them impact the skin, but more importantly to identify molecular conjunction pathways of these different factors in order to get a better understanding of the integrated "genome-microbiome-exposome" effect. For this purpose and in order to translate molecularly the impact of the key influencers of skin health and skin aging, we built a digital model based on system biology using different bioinformatics tools. This model is considering both the positive and negative impact of our genome (genes, age/gender), exposome: external (sun, pollution, climate) and lifestyle factors (sleep, stress, exercise, nutrition, skin care routine), as well as the role of our skin microbiome, and allowed us in a first application to evaluate the effect of the genome in the synthesis of collagen in the skin and the determination of a suitable target for boosting procollagen synthesis. In conclusion, we have, through our digital holistic approach, defined the skin interactome concept, as an advanced tool to better understand the molecular genesis of skin aging and further develop a strategy to balance the influence of the exposome and microbiome to protect, prevent, and delay the appearance of skin aging signs and preserve good skin health condition. In addition, this model will aid in identifying and optimizing skin treatment options based on external triggers, as well as helping to design optimal treatments modulating the intrinsic pathways.
\end{abstract}

Keywords: system biology, interactomics, skin homeostasis, molecular translation, holistic beauty, cosmetics

\section{Introduction}

Our very first barrier between our body and our surroundings is embodied by the skin, which serves a wealth of purposes, ranging from protection to environmental threats, prevention of percutaneous water loss, temperature maintenance, sensory perception, and immune surveillance. ${ }^{1}$ Beyond mere protection, skin health and appearance play crucial roles for self-esteem and social interactions. ${ }^{2}$ 
In the last decades the study of skin ageing led to a split into two identified components, more a less overlapping depending of the individual: an intrinsic component and an extrinsic one. Intrinsic aging stands for the "normal" decay of the skin, associated mostly with chronological age and resulting in thinner skin, wrinkle formation, and a rougher skin surface. ${ }^{3,4}$ In 2015, Trojan et al's ${ }^{3}$ study aimed at disentangling extrinsic from intrinsic biological phenomena on facial skin aging, using both clinical and biophysical methods, concluding that chronological age is a surrogate marker for intrinsic aging. Extrinsic aging, stemming from extensive exposition to the sun or pollutants, overlaps intrinsic skin aging and further aggravates features such as skin firmness, wrinkles, ptosis, and yellowing, to name a few.

However, for a better understanding of the interplay of the human skin with the environment and the subsequent development of the signs of aging and unhealthy skin, a comprehensive knowledge of the totality of lifelong environmental exposure is needed and can be defined as the "exposome". The term was coined by Wild $^{5}$ in 2005, and its definition was notably refined by Miller and Jones ${ }^{6}$ in 2014 , "as the cumulative measure of environmental influences and the associated biological response throughout the lifespan, including exposure from the environment, diet, behavior, and endogenous processes. Krutmann et $\mathrm{al}^{7}$ reviewed the impact of exposome in skin aging, proposing that the principal influencing variables were UV radiation, air pollution, tobacco smoke, nutrition, and cosmetic products.

The impact of exposome effect on chronic disease was quantified in 2016 by Rapoport, ${ }^{8}$, who estimated the effect to $80 \%$, while the genome-wide-associated diseases did not exceed $20 \%{ }^{9}{ }^{9}$

Our microbiota, a collection of micro-organisms, is a living ecosystem both inside (gut) and outside (skin) of our body. Typically located at the interface of our inner and outer barrier of the body, where its main role is to maintain health. ${ }^{10,11}$ Its impact in gut health and disease is widely accepted, but we are just starting to understand the role of cutaneous microbiota and its influence on skin health and aging. So far, it has been shown that cutaneous microbiota is involved in regulating host inflammation, skin barrier, wound healing, and the premature skin aging process ${ }^{12-14}$ as well as, in dysbiotic conditions, linked to various skin ailments. ${ }^{15,16}$ Clearly, there is a strong tête-à-tête between our gut and the skin, where healthy gut also contributes to beautiful skin appearance too. ${ }^{17} \mathrm{~A}$ recent study showed an interesting inverse relation, where UVB light skin exposure is impacting the human intestinal microbiome. ${ }^{18}$ This novel study opens a new vision between two barrier organ bidirectional interactions.

Altogether, our skin health and ageing process is the resulting contribution of the molecular interactions between our wider genome, our microbiome, and the exposome (Figure 1). In this article, we define and review individually how key influencing factors impact the skin and explore a "genome-microbiome-exposome" (GME) approach through a digital model based on system biology, aiming, at molecular level, determining the integrated impact of either the joint GME factors. The ultimate goal being to create a digital holistic tool, to better understand the molecular genesis of clinical signs of aging and further develop a strategy to balance the influence of the exposome and microbiome to protect, prevent, and delay the appearance of signs of aging and preserve good skin health condition.

\section{Genome}

\section{Internal Factors}

\section{Genetics}

\section{Ethnic Skin}

Physical and biological phenotypes of the skin aging processes manifest differently between diverse ethnic populations. ${ }^{19}$ Chinese women exhibit notably lower pore size and density across all the age groups compared to other ethnicities. ${ }^{20}$ Highly pigmented skin individuals have aberrant epidermal architecture, with stalagmite-like structures at the dermo-epidermal junctions, correlating with an enlarged pore size compared to individuals from other ethnicities. $^{20,21}$

Research shows that wrinkles appears at early stages in Caucasian, compared to other ethnic groups. In fact, Chinese women exhibit a prevalence of pigmented spot and a delayed appearance of wrinkles by 10 years, when compared with French women ${ }^{22}$ (Figure 2). Highly pigmented skin individuals have smaller collagen fiber bundles but larger nucleated fibroblasts compared to Caucasian skin individuals. ${ }^{23}$ Compared to Caucasian skin, Asian and dark skin tone have much thicker and structurally more compact dermis. This could be one of the reasons why Asians and dark skin tone individuals have lower incidence of facial rhytids. ${ }^{24}$ Furthermore, stratum corneum of darker skin types exhibits a higher 


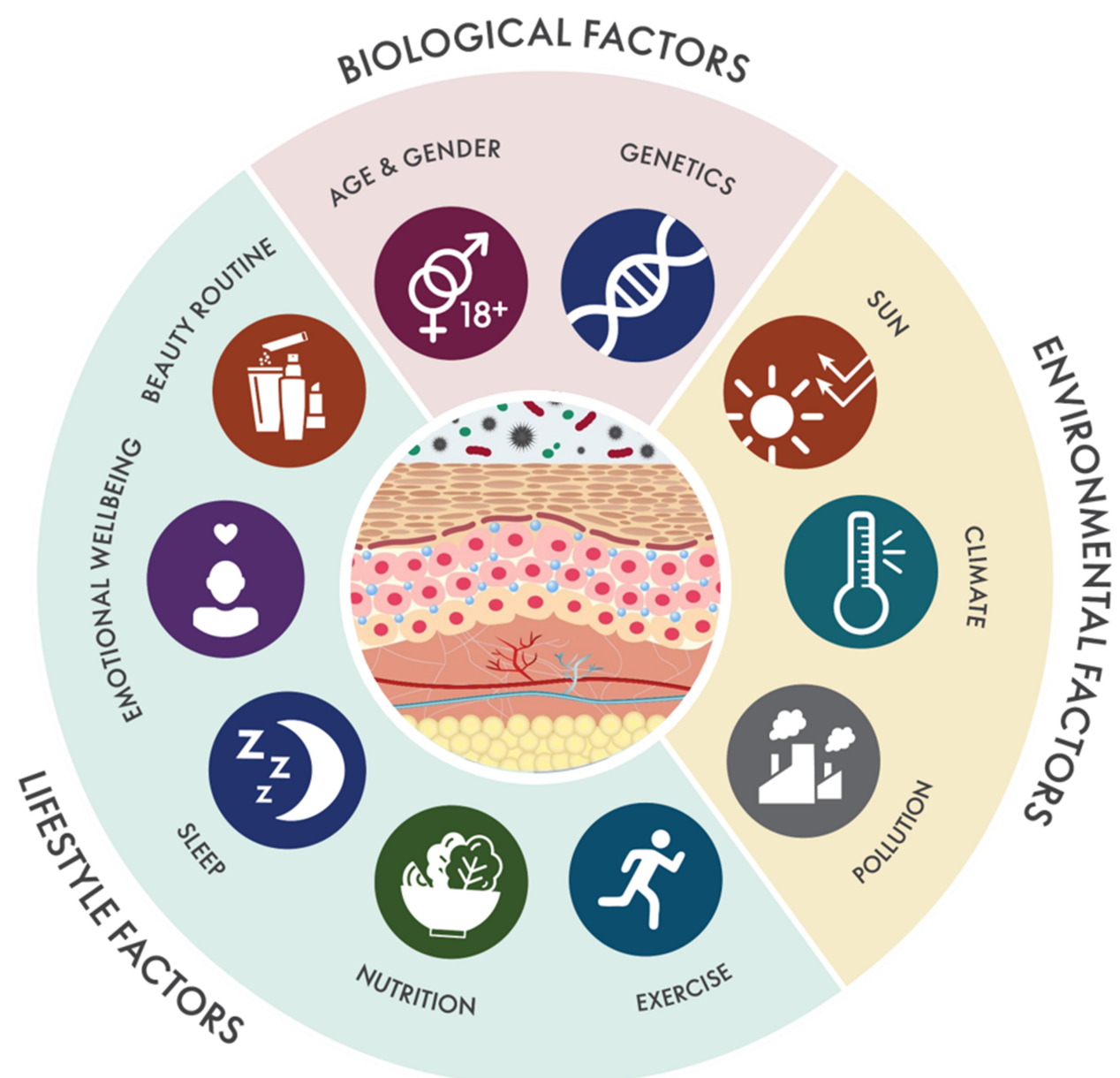

Figure I Holistic Beauty Wheel. Schematic map of the biological, environmental, and lifestyle factors influencing skin health and skin aging.

lipid content and more cornified cell layers compared to the lighter skin. ${ }^{25}$ Studies have also highlighted ethnic differences in the elastin fiber network and in TGF- $\beta$ signaling in African American and Caucasian skin. African Americans have less UV dependent damage in elastin than Caucasian subjects. ${ }^{26}$ Galzote et $\mathrm{al}^{27}$ have studied Asian populations and found declined skin elasticity, epidermal cell turnover, and an increase in collagen cross-links with progress in age, which, in turn, increased the collagen cross-links and are widely associated with advanced glycation end products (AGE), one of the major factors inhibiting skin repair and cell turnover. ${ }^{27,28}$ The most striking dissimilarities when comparing Caucasians skin to darker skin color are both the quantities of melanin and proportions. ${ }^{29}$ Higher skin melanin content provides a stronger advantage against UV rays, photo aging, and cancer. At the same time, darker skin is more prone to be sensitive to hypopigmentation, making uneven skin a typical sign of photoaging on dark skin tone people. ${ }^{30}$ Uneven pigmentation is more frequent and appears earlier in Japanese women than in French women. ${ }^{31}$ Autophagy is another key contributor to the ethnic skin color diversity. It has been documented that keratinocytes derived from Caucasian skin exhibit higher autophagic activity than those derived from African American skin. ${ }^{32}$ With age, both Caucasian and Asian skin becomes darker, but Caucasian skin tone tends be redder while the Asian one tends to be more yellow. Skin redness is due to changes in the microvasculature of the dermis, mostly at the cheekbone area. ${ }^{33,34}$ One interesting study was conducted between different ethnic groups to define skin barrier properties. By measuring the trans epidermal water loss (TEWL), it has been demonstrated that Caucasian skin had strong barrier properties, followed by African, Chinese, and finally Indians. ${ }^{35}$ Yamashita et $\mathrm{al}^{36}$ studied the differences in conditions of ethnic skin to characterize its susceptibility to oxidative stress. The findings show variations of susceptibility to 


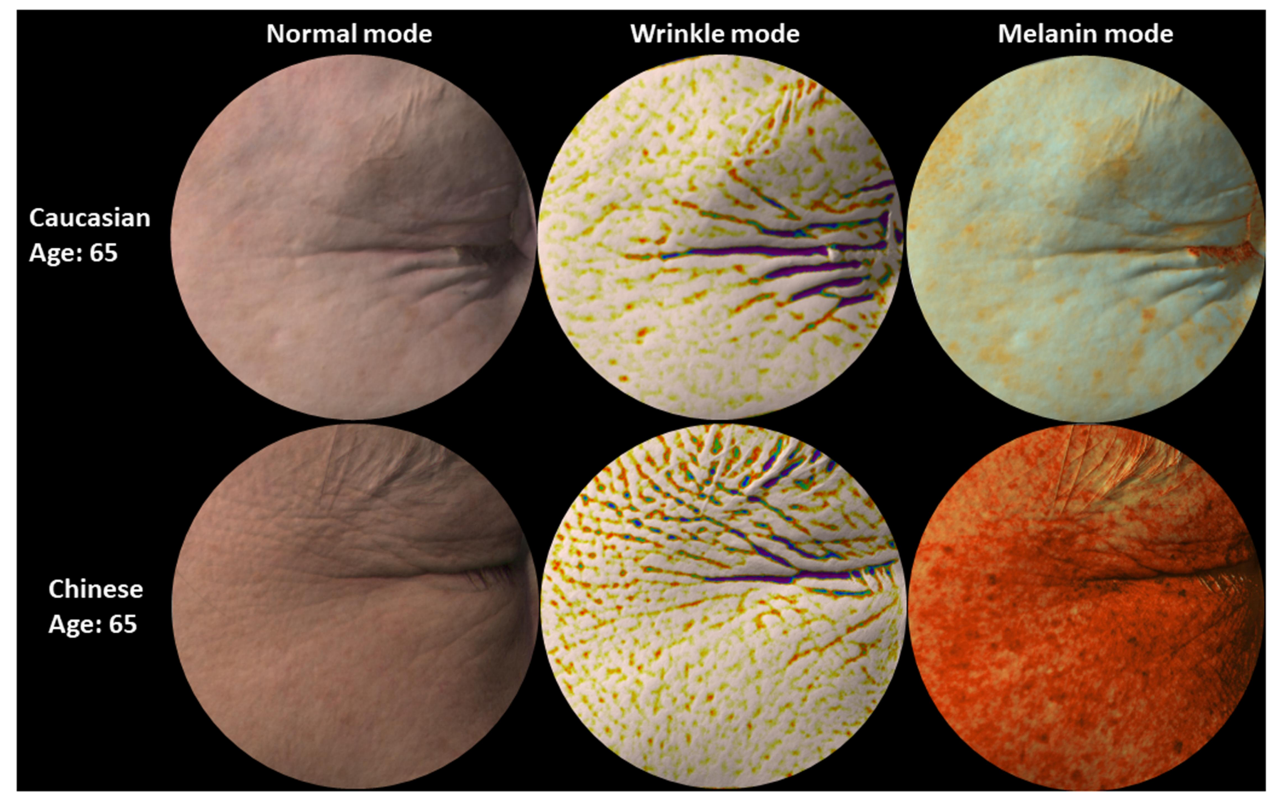

Figure 2 Representative images of Caucasian and Chinese skin. Representative images of 65 years old Caucasian and Chinese facial skin (Crow's Feet) captured with the Antera 3D camera. Starting from the left: normal mode showing images as perceived by the naked eye, wrinkle mode where depressions are highlighted with dark colours (the darker the deeper the wrinkle) and melanin mode where higher concentrations of melanin are rendered in darker orange color. Deeper wrinkles, yet less pigment spots, are observed in Caucasian skin compared to Chinese skin.

oxidation (melanin content and catalase activity in the skin) contributed to better skin conditions in Japanese subjects compared to French subjects.

\section{Age and Gender}

Hormones and gender specific factors may also play an important role in skin morphology and aging process, respectively. Hand male skin has a thicker dermis than females but has a thinner hypodermis, thus suggesting the influence of gender-related hormones. ${ }^{37-39}$ One interesting study involving whole genome screening of sun-protected skin areas show an overlap of just 39 genes, thus pointing out how the process of aging may differ between males and females. ${ }^{37}$

There is an interesting hypothesis of accelerated skin aging process associated to excessive levels of iron and ferritin in menopausal women. Females can lose excess iron both as part of the menstrual cycle and desquamation. Post-menopause, the skin stores the excess of iron ions under ferritin form. Such accumulation of iron exacerbates the amount of reactive oxygen species, possibly accelerating the female skin aging. ${ }^{40}$ Skin aging related progressive decline of skin thickness was associated with the loss of

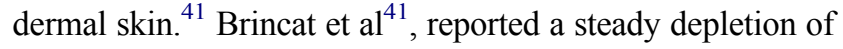
collagen content and a reduced skin thickness following menopause, with yearly reductions of $2.1 \%$ and $1.1 \%$, respectively. These observations were concomitant with the depletion of estrogens, whose beneficial effects on maintaining a youthful skin have been described. ${ }^{42}$ A clinical study aimed at showing the efficacy of a formulation containing $0.01 \%$ of estradiol reported an increased number of fibroblasts following 24 weeks of treatment. ${ }^{43}$ Furthermore, it has been demonstrated that treatment with hormone replacement therapy (HRT) led to significantly improved skin thickness and collagen content vs control ${ }^{44-46}$ Other studies demonstrate that both the skin collagen content and the skin thickness increased in postmenopausal women under HRT compared to controls. ${ }^{47}$ An investigation in a Japanese cohort reported a yearly decline in skin elasticity as measured with a cutometer, though a treatment with HRT for a duration of a year enabled a substantial recovery of $5.2 \% .{ }^{47}$ A study performed on 3,875 postmenopausal women confirmed that oral intake of estrogen has significantly improved skin hydration on the studied panel. ${ }^{48}$ Thus, estrogen deprivation leads to skin dryness, therefore restoring skin moisture with topical moisturizers should be part of the daily skin care regime in women before even entering the menopause phase.

\section{Exposome \\ External Factors}

Sun

The sun's impact on skin health is quite diverse. Sunlight is composed of different wavelengths, penetrating the skin 
at various levels. Here we discuss UVR (ultraviolet radiation) and VL (visible light), including BL (blue light) and IRR (infra-red radiation).

\section{Ultraviolet (UV)}

Ultraviolet radiation is the primary factor of extrinsic skin aging, which accounts for approximately $80 \%$ of facial aging. ${ }^{49,50} \mathrm{UV}$ radiation is a combination of radiations at different energy; UVA (320-400 nm), UVB (290-320 $\mathrm{nm})$, and UVC (100-290 nm). Among them, UVA rays reach the skin deepest layers and induce undesirable changes in the dermis, which are usually followed by early signs of photoaging and in some cases photocarcinogenesis. ${ }^{51-53}$ UVC, on the other hand, are blocked thanks to the protective ozone layer. ${ }^{53}$ UVA is the major portion of the UV making it to the earth's surface, while UVB contribution is less than $5 \% .{ }^{54}$ UVA radiation does affect the oxidative status of skin components, which is well studied for its contribution to photoaging processes. ${ }^{55}$ UVA radiation induces changes in the dermal layer of the skin through the generation of ROS, as shown using reconstructed skin models. ${ }^{56,57}$ Interestingly, the epidermis is not significantly affected. Because UVB hardly reach the dermis, fibroblasts are more affected by UVA and to a higher extent than cells in the epidermis. ${ }^{57,58}$ Using a reconstructed human epidermis (RHE) model, it was shown that UVA induces MMP-1 production in the fibroblasts independent of the epidermis, whereas UVBinduced MMP-1 production requires the epidermis. ${ }^{59,60}$ Additionally, UVA act on genes linked to the skin protective capabilities against oxidation and further promotes photo-aging, such as heme oxygenase-1 and superoxide dismutase-2. ${ }^{61,62}$ Moreover, UVA induces changes in the biological marker expression like ferritin, tenascin and lysozyme, which are described to be associated with photoaging and solar elastosis. ${ }^{56,63,64}$ Repetitive, sub erythemal UVA exposure on the skin induces a strong increase $^{65}$ in the pigmentation, which is particularly important in Asia, where the major signs of skin photoaging are observed. ${ }^{66,67}$ In contrast to UVA, UVB is directly absorbed by the epidermal cells leading to characteristic DNA mutations, and the damaged DNA products subsequently can activate skin melanogenesis, and enable the skin to reinforce its protection against radiation. ${ }^{68}$ UVB deleterious effects can further lead to apoptosis of keratinocytes and generate "sunburn" cells. ${ }^{69}$ In vivo studies highlighted the use of sunscreen could prevent DNA damage, therefore protects the skin risk from melanoma and squamous cell carcinoma. ${ }^{70}$ This in fact proves the UV radiation induced destructive events on the DNA strands. Moreover, chronic and sub-erythemal inflammation is a major component of the aging process, ${ }^{71}$ also called "inflamm-aging" that can initiate or significantly impact the evolution of age-related diseases and skin aging. $^{72,73}$

\section{Visible Light (VL)}

Visible light accounts for about $50 \%$ of solar light and its wavelength ranges between $390-700 \mathrm{~nm}$. It has been shown that IR in combination with VIS led to the overexpression of MMP-9, with a reduced synthesis of type I pro-collagen following exposure to sunlight. ${ }^{74}$

\section{Blue Light (BL)}

Blue light is a range of the visible light spectrum. Interestingly, a recent study showed a direct impact of blue light on circadian rhythm. Blue light disrupts the circadian rhythm and creates damage in skin cells and eventually accelerates aging. ${ }^{75}$ Although of weaker energy (760 nm-1 mm), infrared radiation's (IR) contribution to the earth's temperature is substantial and, therefore, its impact on skin needs must be considered further. ${ }^{76}$ As a result, more and more studies confirm the deleterious effect on IR on the skin: stimulating the expression of MMP-1 in vitro. ${ }^{77}$

\section{Pollution}

Among the several types of pollutants (air, water, soil, noise, radioactive, and thermal), air pollution is the major one, which affects all the living organisms. The common pollutants are particulate matter (PM), volatile organic compounds (VOC), ozone, nitrogen, and sulfur dioxide, both their concentrations and composition of these pollutants vary in countries ${ }^{78}$ across the world (WHO). Skin is the direct target organ and mostly affected by all these pollutants, in addition to the lungs. ${ }^{79,80}$ On Chinese women, chronic exposure to severe outdoor urban pollution in an aggravating factor of facial aging signs ${ }^{80}$ as pollutants are damaging the skin and accelerate premature aging primarily via oxidative stress, then skin barrier dysfunctions, inflammation, and apoptosis. ${ }^{81}$ Topical skincare product may help to prevent and reduce the damaging effects of air pollutant on exposed skin, thus supporting the maintenance of an optimal skin health condition. Particulate matter (PM) is amongst the most common air pollution components. Recently it has been shown that 
PM10 induced dermal fibroblasts have significantly increased the expression of pro-inflammatory genes/proteins, cytochrome P450 (CYP1A1, CYP1B1) and MMPs, as well as a significantly reduced expression of Coll-1- $\alpha$, TGF- $\beta$, and elastin (ELN) mRNA. The incidence of hyperpigmentation disorders, especially melasma (chloasma faciei), is increased in people living in heavily polluted geographic regions like in India and South East Asia. ${ }^{82}$ After entering the skin, pollutants can induce ROS that stimulates the expression of MMPs leading to premature skin aging, especially in the hyperpigmentation skin phenotype. In China, the use of coal, as a solid fuel, generates high indoor air pollution exposure and an increase risk of aging skin. ${ }^{83}$ An interesting comparative clinical study was performed on subjects in more and less polluted areas of Mexico. An increased level of sebum secretion, but with a lower concentration of both squalene and vitamin E, lactic acid and a higher erythematous index on the face were observed in people residing in the more polluted areas compared to less polluted places, thus driving more atopic dry skin, urticaria, and red dermographism and being some the main characteristics of skin from people living in highly polluted areas. ${ }^{84}$ Epidemiological studies showed both facilitate the development of new skin diseases and exacerbate the existing one, as increased PM levels modulate oxidation and pro-inflammatory cytokines in the skin. ${ }^{85}$

A lifestyle pollutant - cigarette smoking, is wellknown to generate not only systemic health complications but also cause premature aging of the skin. Smoking increases oxidative DNA modifications, interferes with the dynamic of telomeres and with the activity of human telomerase reverse transcriptase (hTERT). This was shown by Lotfi et al, ${ }^{86}$ where he described a higher percentage of negative hTERT in the skin of smokers, but a higher percentage of positive hTERT expression was observed among non-smokers, despite non-significant levels. Thus, the potential effects on telomerase activity of smoking could possibly contribute to skin aging processes. Other studies have shown long-term smoking association to cutaneous microvascular dysfunctions ${ }^{87}$ and marked changes in the skin temperature and oxygen content on the face. ${ }^{88}$ Moreover, systematic review and meta-analysis studies associate smoking with an increased risk of basal and squamous cell carcinomas (BCC and SCC) of the skin. ${ }^{89}$ A clinic-based case control study confirmed such association, particularly in women. $^{90}$
These results clearly demonstrate an important impact of pollution on skin quality, potentially on microbiome, as microbiome-related skin conditions are exacerbated, with premature aging and risks for disease development. Therefore, antioxidant, anti-inflammatory, and/or antiseborrheic treatments may be good preventive options as anti-pollution cosmetic products together with ultraviolet (UVA/UVB) protection.

\section{Climate}

When discussing climate impact on skin health, it is important to define a dermatological impact of season variations and global climate change, often in a connection to geographical zone.

Seasonal variations have a big impact on skin appearance and texture. Especially during the winter in northern countries, the risk of skin concerns, such as dermatitis, is increasing due to low temperature and humidity. ${ }^{91}$ In an earlier study, skin seasonal fluctuation from Shanghainese female volunteers was monitored over two 6-month intervals. It turned out that biophysics parameters (eg, oiliness, moisture) and color-related parameters were the most affected, while topographic features (eg, Ptosis, wrinkles) remained constant. ${ }^{92}$ Seasonal variations various skin parameters have been reported in several cities in Asia. Generally, pigmentation and wrinkles were reduced in the winter compared to the summer, while other features such as skin barrier and moisture, for instance, worsened. ${ }^{27}$ Another interesting study in Korean females showed the seasons induce changes in skin hydration, sebum content, scaliness, brightness, and skin elasticity. ${ }^{93}$

Climate change seems to be evolving at a record pace because of the impact of human and non-human-related activities on the environment. Despite the extensive research on how climate change could alter health systems, so far very few studies have been carried out to explore the consequences on skin health. ${ }^{94}$ The skin is the barrier between the rest of the body and its environment; thus, it is expected that cutaneous alterations may occur in a response to climate change. Drier environmental conditions increase the permeability of the epidermis, ${ }^{95}$ with lower humidity that stimulates the production of epidermal inflammatory mediators and promotes hyperproliferative response. ${ }^{96,97}$ Moreover, cold temperatures and dry conditions have been linked to a higher rate of irritations. ${ }^{91}$ Furthermore, it has been outlined that sebum levels are generally higher in younger patients and during warmer months. ${ }^{98}$ Daily skin exposure to a low-humidity 
environment induces a lower water content in the stratum corneum and accentuates fine wrinkles related to skin dryness. $^{99}$

Thus, a climate conscious skin care product development considering seasonal variations and global climate change specific to the geographical zone is another important consideration for consumers.

\section{Lifestyle Factors}

Sleep

Sleep is important for growth and renewal of multiple physiological systems, including the skin. One interesting study conducted on 60 healthy Caucasian women showed chronic poor sleep (duration $\leq 5$ hours) quality was associated with a reduced skin barrier function, an increase of facial signs of aging, and a lower satisfaction with attractiveness and appearance, compared to good sleep (duration 7-9 hours). ${ }^{100}$ Moreover, acute lack of sleep impacts skin barrier, hydration, elasticity, pores, translucency, brightness, and blood flow. ${ }^{101}$

Although the actual sleep is controlled by the central nervous system, melatonin and cortisol are hormones that play a huge part in determining our circadian rhythms and the quality of sleep in general. Since skin aging mechanisms are not fully understood, new aspects of skin healthiness such as melatonin are introduced. Melatonin secretion is light-dependent of circadian rhythm and its receptors are expressed in the most skin cells, including keratinocytes, melanocytes, and fibroblasts. ${ }^{102}$ Recently, Rusanova et al $^{103}$ summarized a wide range of protective effects of melatonin such as strong anti-inflammatory, antioxidative activity, mitochondrial protection, photoprotection, and anti-wrinkle /skin damage. Thus, melatonin is considered as one of the effective active agents for skin health to boost skin defense and protection systems to prevent it from external aggression.

\section{Exercise}

During exercise, oxygen and nutrient rich blood are delivered across the body through the highly regulated integration of central and peripheral hemodynamic factors. ${ }^{104}$ Interestingly, it was found that exercise until exhaustion changes the skin content of NADH, modifies NADH turnover at rest, during ischemia, and reperfusion in the most superficial living skin cells. ${ }^{105}$

Intense exercise leads to sweat, which helps the skin to keep clear, as when we are sweating, the pores flush out toxins that need to be washed properly afterwards, as they can lead to irritation and blemishes. ${ }^{106}$ An earlier study showed that exercise-induced sweating significantly affects the skin physiological properties of the facial region such as SC hydration, sebum secretion, and surface pH. ${ }^{107}$ Exercise also helps to maintain cortisol at healthy levels, as spiked cortisol levels can induce several types of skin damage, such as breakouts or increase of collagen break down, resulting in an acceleration of wrinkles formation and skin sagging. Working out triggers collagen production to help maintain healthy skin. Crane et al ${ }^{108}$ showed that exercise induces IL-15, a novel regulator of mitochondrial function in aging skin. It is well known that regular exercise has multi-system anti-aging effects, including skin ${ }^{109}$ and muscles. The more strong, firm muscle tone is associated to the healthier looking skin, because of better support.

Thus, besides developing novel anti-aging targets in the skin, more effort should be devoted to educating consumers that exercise contributes greatly to healthier looking skin when combined with a skin care routine.

\section{Nutrition}

Already the ancient Greeks such as Hippocrates and Dioscorides, author of Materia medica, had a good understanding that diet is relevant for overall health. Ancient literature for example described oat properties as being both anti-inflammatory and anti-itching, which today is still widely used and refined due to its high content of micronutrients with multifaceted health benefits. ${ }^{110}$ Today we are still discovering novel insights on how the nutritional intake can influence our health and specifically our skin health, down at the molecular level.

\section{Vitamins, Minerals, and Antioxidants}

Some of the most studied micronutrients with beneficial effects on skin health, both from oral and topical applications, are essential vitamins and antioxidants. Vitamin $\mathrm{C}$ is broadly used as a supplement and has multiple benefits on our overall health, associated with maintenance of our immune system as well as protecting DNA, proteins, and lipids from oxidative damage. ${ }^{111}$ Vitamin $\mathrm{C}$ also has similar benefits in the skin, both as an antioxidant driving photoprotection and reducing skin pigmentation, but also in terms of affecting synthesis and improving the stability of collagen protein in the skin. Other essential vitamins with specific skin benefits are Vitamin E (tocopherol) which can work synergistically with Vitamin $\mathrm{C}$ in terms 
of photoprotection, ${ }^{111}$ and Vitamin B3 (nicotinamide) in restoring cellular energy, repairing damaged DNA, and reducing the immunosuppressive effects of sun-induced UV rays.

Vitamin A active compounds (retinol, retinyl esters, retinaldehyde, retinoic acid) are widely used for skin health purposes due to their multifunctional beneficial roles in relation to acne treatment, pigmentations and regulation of matrix proteins such as collagens. Through our diet we get a supply of dietary retinyl esters (RE) and carotenoids, found in fruits and vegetables. In the skin, RE is converted to the bioactive form of retinoic acid (RA), which can modulate an extensive gene machinery in various skin layers, and thus exhibit a strong activity on the skin. ${ }^{111}$

\section{Carotenoids}

$\beta$-carotene, an endogenous photoprotector, is known for its efficacy to prevent UV-induced erythema formation ${ }^{111}$ and dietary supplementation can further enrich $\beta$-carotene skin concentration.

The ketocarotenoid astaxanthin is naturally produced by plants, bacteria, and microalgae. Haematococcus pluvialis, a chlorophyte alga, is certainly the one having the highest capacity for astaxanthin accumulation and therefore has served as the principal source for dietary supplements, cosmetics, and food. ${ }^{112}$ Multiple studies have shown various skin health benefits of oral supplementation of astaxanthin through different mechanisms, such as prevention of oxidative stress, inhibition of inflammatory mediators, as well as suppression of hyperpigmentation and wrinkle formation. ${ }^{113}$

Healthy skin is also dependent on a constant supply of minerals such as Zinc, Copper, and Selenium. These minerals can act as enzymatic cofactors for glutathione peroxidases and superoxide dismutase (SOD) and can thus support in eliminating free radicals and thereby preventing oxidative stress indirectly. ${ }^{114}$

\section{Polyphenols}

Polyphenols are the major secondary pants metabolites, formed with at least one phenolic unit. Accordingly, simple phenols are named phenolic acids, intermediate ones are flavonoids and anthocyanins, and high molecular weight polyphenols are stilbenes, coumarins, and tannins. ${ }^{115}$ Polyphenols are found in many different plants and berries and the composition and proportion of polyphenols may vary depending on plant family and extraction procedure. ${ }^{115,116}$ Phenolic compounds can benefit skin health through many different mechanisms such as activation of specific cellular pathways, antioxidants, and acting as prebiotics that can influence the skin microbiome. ${ }^{115,117}$

\section{Fatty Acids and Ceramides}

Human stratum corneum structure and skin barrier integrity results in a original composition made of $50 \%$ ceramides, $25 \%$ cholesterol, and $15 \%$ free fatty acids. Ceramides are involved in several biological processes and lipid raft-mimicking mixtures and studies have shown that reduced levels of ceramides are shown in skin barrier altered diseases such as atopic dermatitis and psoriasis, while being identified as a hallmark of skin aging. ${ }^{118}$ Ceramides used for therapeutic purposes have traditionally been obtained from bovine or biotechnological sources. However, lately skin-like ceramides have also been isolated from edible plants, such as rice, sweet potato, and wheat. Some of the plant derived ceramides, such as glycosyl ceramides from wheat, have been shown to clinically improve skin hydration and symptoms of aging as well as skin barrier repair through oral supplementation. ${ }^{118,119}$ Polyunsaturated fatty acid (PUFA) are essential fatty acids such as linoleic acid, arachidonic acid ( $\omega-6)$, and in particular W-linoleic acid $(\omega-3)$ that are of critical importance for skin health, due to their potential applications in disease prevention, but also treatment of the most common inflammatory skin diseases, such as atopic dry skin acne and psoriasis. The benefits of PUFA seem to involve multiple mechanism of actions both via receptors regulating signaling processes that influence patterns of gene expression via eg PPAR $\gamma$ as well as more direct changes in cell membrane fatty acid composition. Whereas Omega-3 is often sourced from fish oil, Omega-6 can be found in the plant kingdom in sources such as safflower oil, flaxseed oil, and soybeans. ${ }^{120}$

\section{Emotional Balance/Stress}

\section{Skin Health}

In the previous sections of the article, we extensively reviewed the contribution of factors upon the skin, many of them leading to changes visible to the naked eye. These perceivable skin features can, in turn, be used to make an assessment about our peers in terms of attractiveness, although not consciously, and an evolutionary psychologist would argue that it could ultimately serve the purpose 
of finding a "healthy" mate. ${ }^{121}$ We did show that the cues for age and health perception can vary according to the ethnic skin background, by showing similarities and dissimilarities between Russia, Indian, and China, ${ }^{122}$ and would be very much due to a combination of external factors, such as climate, pollution, genetic, but also distinct cultural background.

More recently, we aimed at showing the dichotomy between perceived age and perceived health in a Chinese cohort using a Machine learning approach. Some skin features were specific to age perception (eg, eye bags, eye lid sagging, wrinkles), while others were rather related to health perception, such as pigmented spots, acne, scars, or skin hydration. ${ }^{123}$

\section{Mental and Body Health}

Beside maintaining an outer skin health, through a protective role and skin nourishments, cosmetics and beauty routines also help to improve one's appearance, resulting in positive effects in one's self-perception, confidence, and perception by others. ${ }^{124,125}$ The feel good factor boosts our self-esteem and improves our performance, which favorably affects what others think of us, and how they behave towards us. Recently an original hypothesis discussed the contribution of impaired epidermis on both local inflammation and, more interestingly, body overall cytokines levels. Treatment with a formulation aiming at improving the skin led to a concomitant reduction of content of cytokines in the body. ${ }^{126,127}$ Thus, an innovative strategy to prevent or address systemic "inflamma-aging" could be the use of relevant topical preparation, therefore enforcing the benefit in maintaining good skin health to balance the overall inflammatory status of the inner body.

It is well known that there is a significant association between stress and individuals' health, including a negative effect on many dermatological diseases. ${ }^{128}$ Unfortunately, there is a lack of data that impact stress on disease-free skin. One interesting study was done on a small group on female students, with timepoints such as intense stress (exams) and control period (after holidays). In summary, psychological stress induced disturbance on the epidermal barrier function both through a disruption of the barrier function as well as a delay on the barrier recovery, in healthy individuals. ${ }^{129}$

Another cross-sectional study between psychological stress and skin symptoms was done among 529 medical students. Results showed that older age, female gender, and being during exam weeks were associated with the highest perceived stress levels associated with oily, waxy patches or flakes on scalp, dry/sore rash, warts, pimples, itchy skin, and hands itchy rash, among other symptoms. ${ }^{130}$

A possible explanation of how stress affects skin conditions was shown on an AD model, where an acute stress triggers a fast release of stress hormones, which further activates the immune system, primarily through Th1 cells, producing pro-inflammatory cytokines that stimulate inflammation and the associated cellular immune response. In addition, under chronic stress, the skin increase of basal cortisol levels reduces it's capacity to respond to acute stress, as the immune system is shifting from a cellular to a humoral response. And, finally, the keratinocytes, through their receptors for neurotransmitters and stresses, hormones actively contribute to the psychoneuroimmunological pathways. ${ }^{131}$

\section{Gut-Brain-Skin Axis - Skin Benefits of Oral Pre- and Probiotics}

The human skin is the host tissue for microbial communities, living in a symbiotic relationship and through advanced signaling that is relevant for our immune system. A wealth of investigations have outlined the interconnection of the skin and gut commensal populations, ${ }^{17,132}$ with a recent reporting that Body Mass Index influenced both skin and gut microbiomes, but not the oral one. ${ }^{133}$ The gut microbiome ability to mitigate UV-induced deleterious effects, thus preventing photoaging, has been shown. ${ }^{134}$ It is therefore attractive to evaluate the potential beneficial role of oral probiotic supplements in relation to UV protection and skin aging benefits. Indeed, ingestion of Lactobacillus plantarum has shown the inhibition of MMP-1 expression in fibroblasts, showing a potential preventative benefit on UVinduced photoaging in mice. ${ }^{135}$ This anti-aging benefit was also observed in vivo, where oral supplementation of the specific L. plantarum strain HY7714 led to improved skin moisture and biomechanical properties. ${ }^{136}$ A building block of the probiotic strain Lactobacillus, Lipoteichoic acid, has demonstrated anti-inflammation efficacy. ${ }^{137}$ Over 80 years ago, dermatologists John H. Stokes and Donald M. Pillsbury proposed a gut link to emotional imbalance and skin conditions such as acne. Based on their theories, stress and anxiety alters gut microflora, leading to increased intestinal permeability and consequently 
contributing to systemic inflammation in acne susceptible individuals. ${ }^{138}$ To cut off this viscous cycle, it was suggested that both probiotics and antimicrobials may play a role at the gut level. ${ }^{139}$

\section{Beauty Routine}

Usage of cosmetic products is well documented, with early records among various old civilizations. Egyptian men and women used makeup, eyeliner and eyeshadows in dark colors, to enhance their appearance. ${ }^{140}$ Along centuries, knowledge and standards for their fabrication have evolved, with new galenic removal of questionable ingredients that could be toxic if not lethal, etc. Today, product safety and efficacy are ensured through various regulations across the world, and the EU Cosmetic regulations is the most stringent.

In recent times, skin health and beauty have been perceived as an indicator of one's health, which has resulted in an increasing demand for more and more advanced skincare products. UV protectants are amongst the most efficacious products to prevent photo-aging, hyperpigmentation, and skin cancer. ${ }^{141}$ Even though not being recognized as a term, cosmeceuticals refers to cosmetics that deliver a physiological skin benefit through either pure chemicals or natural active ingredients. ${ }^{142-146}$ These are being used in anti-aging, barrier function improvement, anti-inflammatories, UV/pollution protection, and moisturization.

As mentioned earlier (under mental body health), it has been recently demonstrated that topical emollients are able to reduce epidermal circulating levels of proinflammatory cytokines, as a new approach to prevent and mitigate certain inflammation-associated chronic disorders in aged humans. ${ }^{126}$

\section{Skincare Regimen}

Overall, daily use of several skincare products becomes extremely important for skin health, and the backbone for such a beauty routine is designed around a multi-step skincare regimen. Well-known in Asia and notably in Korea, a multi-step regimen is getting further attention for the complementary effects of each step as well as an expected stronger clinical efficacy. However, most of the clinical studies are focusing on active/a formulation, vs either placebo or baseline. So far very few clinical studies have been comprehensively designed and published to demonstrate the additional boosting effect of a multistep regimen. The ones published are mainly related to dermatological issues such as acne, xerosis, and pruritus or one acne-prone skin., ${ }^{147,148}$ Relevant skin care regimen can target the previously identified signs of unhealthy perceived skin after 1-month product usage. ${ }^{149}$ Sticking to a skin care regimen over a period of 6 months can prove beneficial, in comparison to shorter length of use. As outlined by Figure 3, the average decrease of the crow's wrinkle depth among the female volunteers $(n=20)$ was incremental and observed until 6 months.

\section{Microbiome}

Our microbiota, a living ecosystem of skin outer barrier, plays an important role in maintaining health. ${ }_{-}^{11}$ Skin microbiome is largely affected by genome (age and gender, genetics) ${ }^{16}$ and exposome (external and lifestyle factors). In aging skin, significant alteration of skin surface physiology including $\mathrm{pH}$, lipid composition, and sebum secretion, is occurring. ${ }^{150-153}$ These physiological changes may impact skin microbiome composition as well. ${ }^{154,155}$ Shibagaki et al's ${ }^{156}$ study showed that the old aged group exhibited a trend for a higher alpha diversity (species richness) compared to a young group for all tested sites, although the most striking differences were observed on the cheek and forehead. The study also implies differences in beta diversity due to age (changed bacterial communities), on the scalp and forearms areas, being more diverse over time. ${ }^{13}$ Recent AD (atopic dermatitis) study suggested that both pediatric and adult $\mathrm{AD}$ are under influences of various microbes, where childhoodassociated skin bacteria (such as Streptococcus) are replaced, at puberty, by adult-associated commensals (Propionibacterium and Corynebacterium) and in relation to increase sebum production. Unique porphyrin and chlorophyll metabolism for both Propionibacterium and Corynebacterium may provide relevant options for skin health additional protection in adults. ${ }^{157}$

Others showed that the effect of UV on immune function and cell response is modulated by skin microbiome by creating anti-inflammatory environment. ${ }^{158}$ This is in line with other investigations showing that microbial derived metabolites, resulting in an UV-induced immunomodulation, would have a protecting effect against skin neoplasia. ${ }^{159,160}$ In addition to this, we showed that lactic acid secreting Lactobacillus reuteri DSM 17,938 in both live (probiotic) or lysate (postbiotic) format could protect skin from UVB induced inflammatory damage by suppressing pro-inflammatory IL-6 and IL-8 cytokines. ${ }^{161}$ In another investigation, reconstructed Human Pigmented 
A

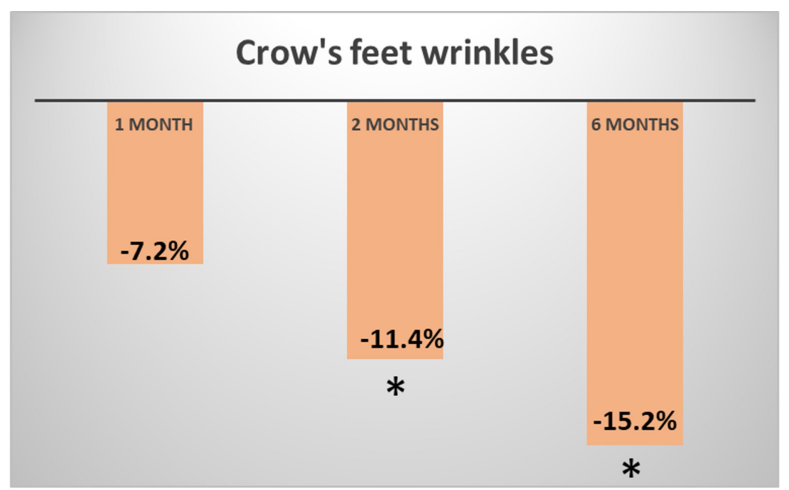

B

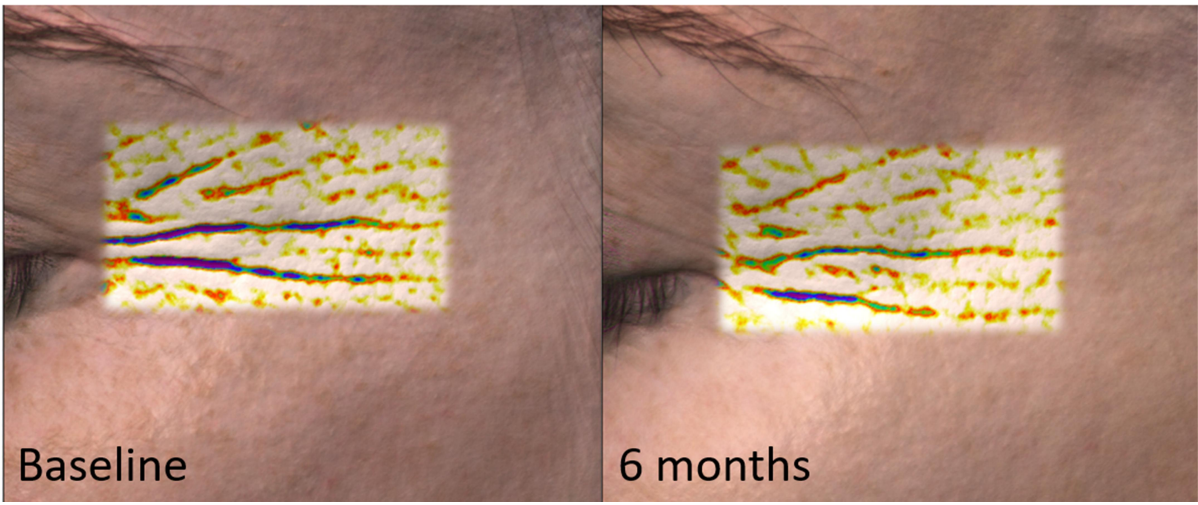

Figure 3 Example of anti-wrinkle benefits of multi-step regimen over 6 months. (A) Mean Crow's feet wrinkle depth percentage reduction on the tested panel using a 4-step skin care regimen, as measured by the Antera 3D. Consistent and incremental efficacy could be observed over a period of 6 months. *Significance vs baseline (Repeated measures ANOVA with Dunnett post-hoc, $P<0.05$ ). (B) Representative image of one volunteer crow's feet area at baseline and following 6 months of using the 4-step skin care regimen. The depression in the skin are depicted in lighter colours at 6 months, showing a reduced depth of the wrinkles.

Epidermis models inoculated with Staphylococcus epidermis were shown to mitigate UV mediated (2 MED) inflammation and oxidative stress by inhibiting NFKB translocation, reducing sunburns, reducing melanosome transfer, and modulation of $\beta$-defensin 2 expression. ${ }^{162}$

Blue light (BL) has been found to have a positive impact on skin health by modulating microbiome and is currently used as light-based therapies for targeting acne. Porphyrins that are naturally produced within sebaceous follicles by Cutibacterium acnes (C.A.) can absorb light. ${ }^{163}$ Wavelengths of $415 \mathrm{~nm}$ within the BL spectrum are the most effectively absorbed, that lead to photoexcitation of porphyrins and subsequent release of singlet oxygen and reactive free radicals that exert bactericidal effects on C.A. ${ }^{164}$ Light-based acne treatments may be potentially effective in acne improvement by reducing acne inflammation lesions ${ }^{165}$ and reducing pathogenic bacterial load. $^{166}$

Studies also suggested that the exposome may impact our skin microbiome. ${ }^{167}$ Several Asian studies were reviewed, and a direct link has been observed between an increase in prevalence of acne and high levels of airborne pollutants. ${ }^{168}$ Elevated levels of pollutants were associated with an increased acne-related outpatient visiting dermatology clinic in Beijing, shown by a time-series study. ${ }^{169}$ Another comprehensive study performed in two different cities in China, one of them being substantially more polluted than the other, reported differences in microbiome that may be driven by polycyclic aromatic hydrocarbon (PAHs), concomitant with increased acne and dandruff. Among the impact on microbiota, we can cite an increase of Shannon diversity index, a reduction of commensal bacteria to the benefit of pathogenic oral bacterial detrimental to the skin, a reduction of the metabolism of amino acids/vitamins in the skin and a reduced microbial network integrity. ${ }^{170}$ Recently, it was demonstrated that a continuous psychological stress can impact skin microbiota, which is probably not surprising, since skin is one of the main neuroendocrine organs and many cutaneous hormones and neurohormones can modulate bacterial physiology. ${ }^{171}$ Briefly, the total numbers and the relative abundance of Corynebacterium, Propionibacterium, and Staphylococcus were increased in the stressed group vs the unstressed group. Moreover, lactic acid producing bacteria such as Lactobacillus and 
Lactococcus increased with stress by $59 \%$ and $67 \%$, respectively. This increase indicated acidification of the surface of the skin and therefore decreased skin $\mathrm{pH}$ compared to unstressed skin. ${ }^{172}$ There is a lack of data about the impact of sleep quality upon skin microbiome, though recent data showing its impact on gut microbiome diversity should encourage skin scientists to carry out investigations with regards to skin microbiome and sleep. ${ }^{173}$

Extensive skin care routines and unsuitable products can trigger acne spots by modifying the skin microbiota, particularly in zones rich in sebum, and consequently trigger inflammation. But it is important to keep in mind that not all C.acnes are harmful for the skin. A recent study showed that certain C. acnes's secrete RoxP, an exogenous antioxidant that naturally occur in the skin, which have a positive impact on the human host by modulating redox status. ${ }^{174}$ Some investigations have pinpointed that the usage of personal care and make-up product leads to changes in skin bacterial diversity, though the implication is that these changes are not yet fully understood and warrants further work. ${ }^{175,176}$

Thus, our skin is largely affected by microbiome, genome, and exposome, through a complex interaction between these three components. To further illustrate the complexity of this interplay, Figure 4 outlines reported relationships between the aforementioned factors upon microbiome and skin features. Despite the current knowledge in the literature, when it comes to the link between exposome, microbiome, and the skin, there is an incredible number of gaps (eg, Sleep, diet, cosmetics) that require additional investigations that can capture these complex interactions.

\section{The Need for a Molecular Translation of the Holistic Concept: The Skin Interactome Model}

Based on reviewed articles and own observations, it is undeniable that skin aging processes are affected by numerous different factors that can also differ depending on our ethnic heritages. Ethnic skin aging mechanism diversity considering age and gender (genome), the impact of microbial ecosystem (microbiome) and multiple external and lifestyle factors (exposome) are some of the main factors affecting skin aging reported in this review. In the near future, in order to mitigate the negative impacts of such factors, further development of the nascent holistic approach will be important for the cosmetic field. In particular, a holistic approach is essential to understand how the sum of each factors are affecting skin health and skin aging on the individual level and how to further define the appropriate recommendations, such as lifestyle changes,

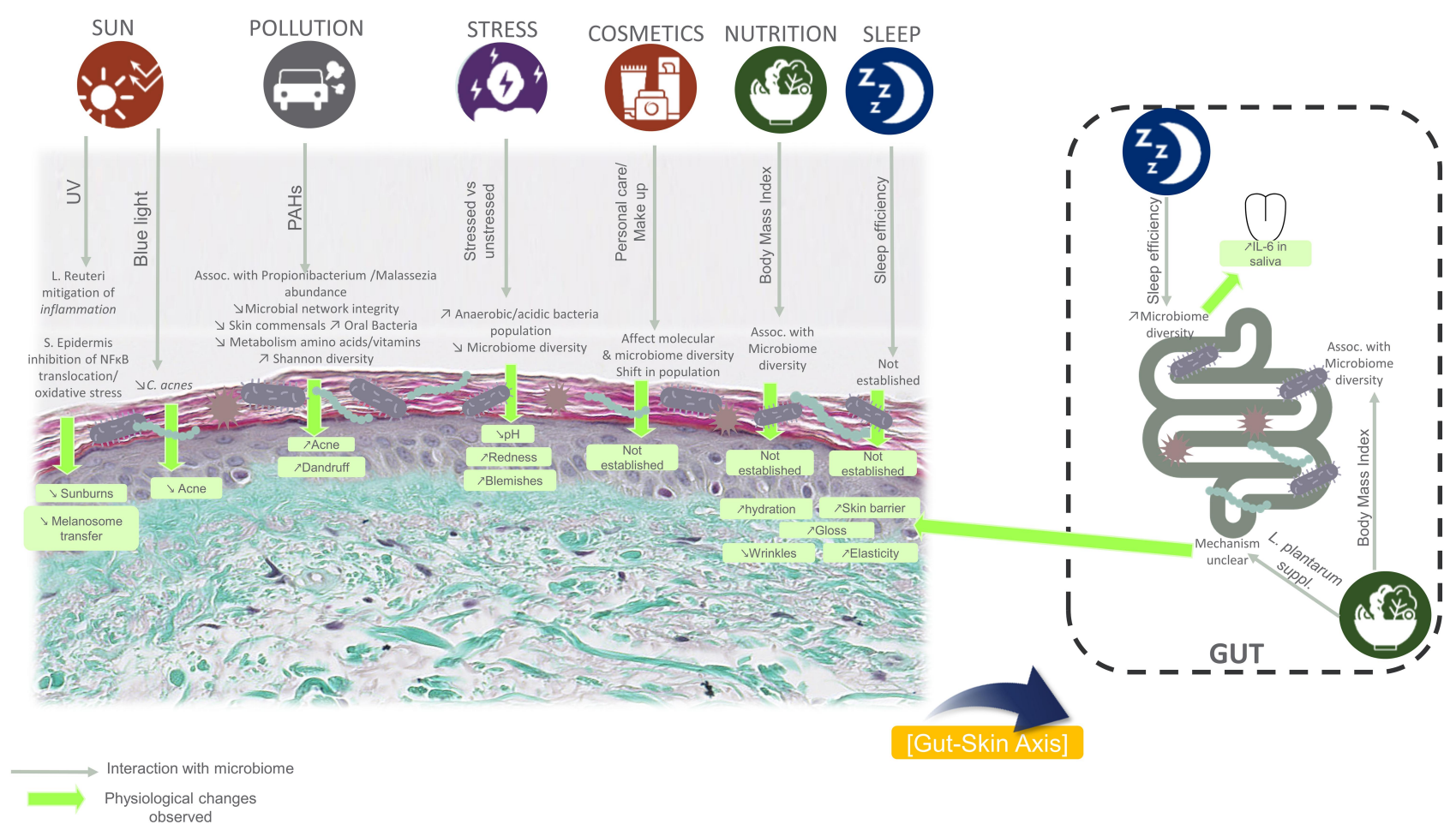

Figure 4 Reported relationships and interactions from the literature between exposome/lifestyle factors, microbiome, and underlying physiological changes. 
nutritional adjustments, adequate cosmetic formulations, and personalized beauty routine, to mitigate the negative impacts of such factors (Figure 5). It is undeniable that factors influencing skin health and skin aging processes are mostly acting through modification of molecular interactions in skin cells and definitively alteration of their homeostasis. Based on the complexity of the holistic approach and the recent development in the interactomics and system biology fields, ${ }^{177}$ it appears evident and necessary to have an adequate biological/mathematical model. A model capable of identifying the molecular players responsible for the skin aging processes in response to the external stress factors exposed in this review, and thus offering a valuable tool to discover and influence new targets mitigating these aging processes, is essential for this model to link the molecular network-based Interactome map (Protein-Protein interaction) of the skin cells and the factors that influence it (genome, microbiome, and exposome) offering a better understanding of the mutual and simultaneous interactions between those factors and their effects in the skin homeostasis. We define this model as the "Skin Interactome", a novel integrated "genome-microbiome-exposome" (GME) approach that will represent the core tool for the identification of the key targets involved in the skin aging process and better address the development of new active ingredients. In the recent years, we have sequentially built this in silico molecular network model for the skin. Starting by mining literature data, using different public and commercial repository databases ${ }^{178,179}$ we obtained a preliminary dataset containing general values for human tissues. After obtaining the raw data, the initial database has been refined by eliminating the proteins not expressed in the skin tissue and identify their cellular and subcellular localization by crossing the preliminary raw dataset with protein expression/localization values obtained from Human Protein Atlas. ${ }^{180}$ The mode generated thus represents a full map of the protein-protein interactions specific for the skin, with data available to date (2017). In addition, it has been connected in a subsequent step with GME factors, through molecular and physical interaction and gene expression modifications described in the literature. This initial model allowed us in a first application to understand how the genome influences the synthesis of collagen in the skin. ${ }^{181,182}$ By this approach, we extracted a sub-network from skin interactome representing the collagen homeostasis in the skin (Figure 6A) and allowing us to determine suitable targets for boosting pro-collagen synthesis. Between the candidate targets identified, the final target was selected and used for the further selection of an appropriate natural bioactive to stimulate the collagen synthesis. In order to select the most efficient bioactive ingredient, we used a methodology developed in house during the last years, ie, the Network-Pharmacognosy approach. ${ }^{183}$ This methodology resulted in an in-silico screening based on chemogenomic data analysis using a large dataset of natural compounds and their origin. Merging the active chemical profile of natural substances reported in the literature vs the selected target yielded a novel, patentable plant extract that acts safely and

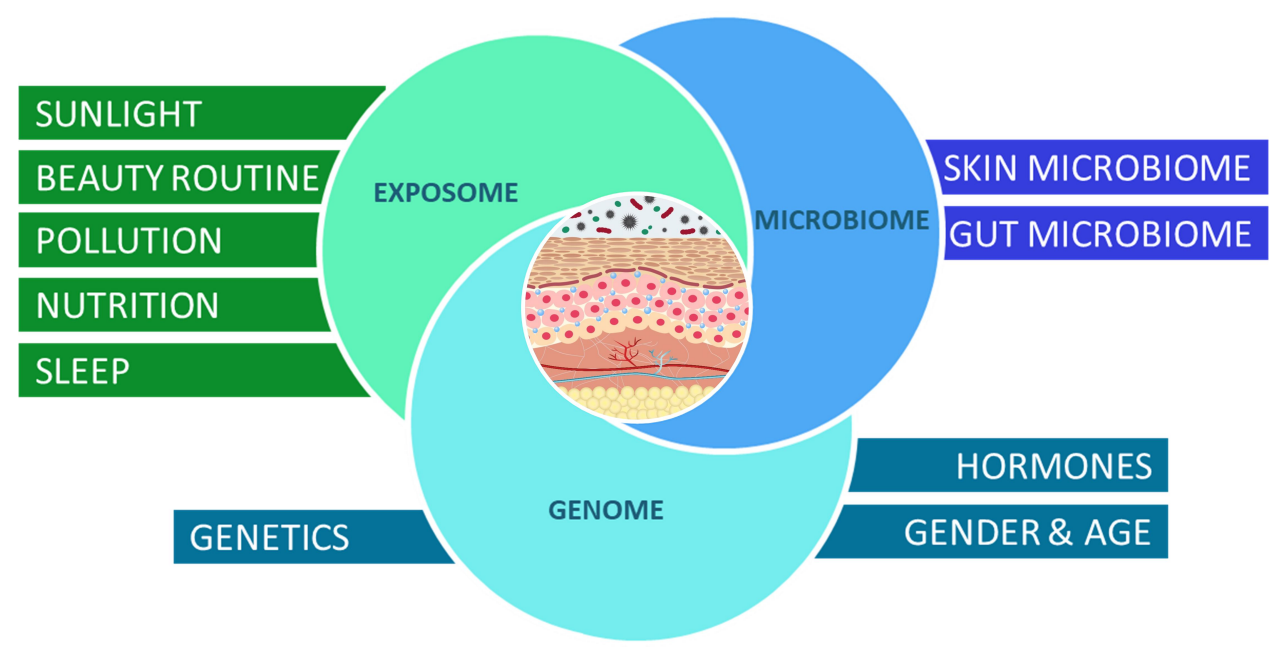

Figure 5 Skin interactome. Schematic view combining the various factors affecting skin health and skin aging in relation to the "genome-microbiome-exposome" (GME) interfaces.

Abbreviations: G, genome; M, microbiome; E, exposome. 


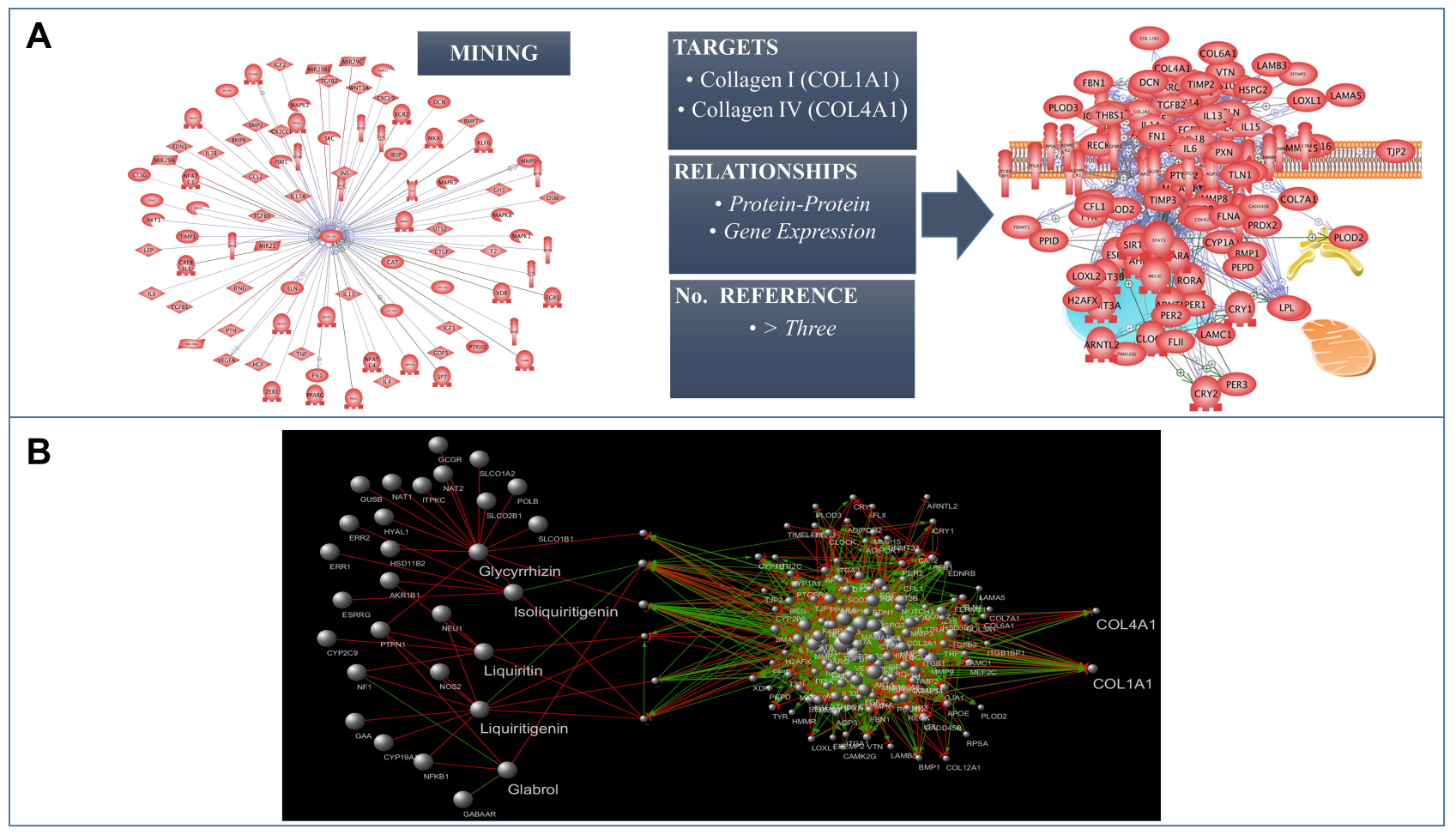

Figure 6 Skin interactome approach applied to the generation of a Collagen IAI/Collagen4AI molecular network model (A) and example of application of Network Pharmacognosy for the determination of the suitable natural plant extract in boosting pro-collagen production (B).

effectively on boosting pro-collagen expression (Figure 6B). ${ }^{181}$ This first application of the skin interactome model encourages us to continue using this tool to try to understand at a molecular level, how different factors affect each other and how they affect skin homeostasis. An additional example of our ongoing work is represented

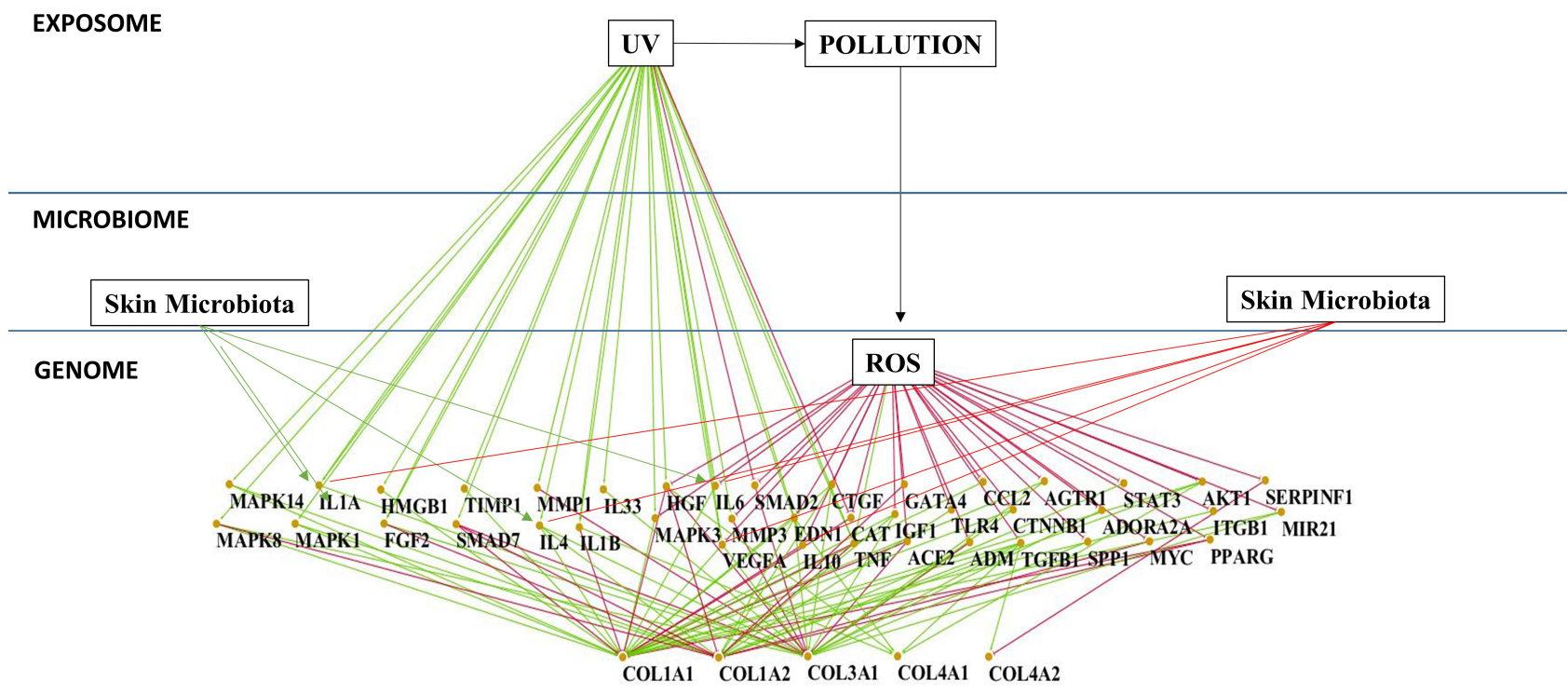

Figure 7 Genome-microbiome-exposome key's interaction and the effects in the collagens skin homeostasis through the mediation of ROS. The illustration shows nodes (proteins) and their interactions obtained by literature data evaluation of an upstream Pi-Pi network for COLIAI, COLIA2, COL3AI, COL4A2 in human cells and the interaction with UV, ROS, Pollution (Diesel Particulate Matter), and Skin Microbiome. 
in Figure 5. This new network model, extracted from the skin interactome, illustrate the influence of the UV/pollution (exposome) and ROS (genome), and the indirect impact of skin microbiota on ROS driven downstream mechanisms impacting the collagen homeostasis (Figure 7). Why ROS? As summarized earlier in this article, ROS play a central role in extracellular matrix alterations leading to premature skin aging. ROS, produced from different intra-cellular sources, the Fenton reaction, by several enzymes, oxygenases, cyclooxygenases, oxidases, and by UV radiation, trigger several downstream signaling pathways, like the activation of MAPK, and subsequent NF- $\mathrm{B}$ as well as AP-1. Activated NF- $\mathrm{BB}$ and AP-1 MMP gene transcription reduce the production of new collagen which results in decreased collagen content of the photoaged skin.

This ongoing development of a new holistic model, that also includes the microbiome, represent a first step in understanding, in a more holistic way, the skin ageing processes and their response to different factors like genome and exposome. In conclusion, the skin interactome model will be essential for molecular understanding and translation of new emerging holistic concepts in the cosmetic field into new more efficient activites in connection with change in habits.

\section{Methods}

References were found through a literature search first on PubMed and with an additional review of relevant textbooks and textbook chapters. The main keyword used in the search was "skin", in combination with the following words: health, aging, exposome, ROS, UV, pollution, climate, ethnicity, menopause, exercise, stress, skin care, nutrition, microbiome, etc. Most of the articles were reviewed for relevancy from mainly 2010 to 2020 .

\section{Genome-Microbiome-Exposome's Model}

The nodes (proteins) and their interactions were obtained by literature data evaluating the upstream Pi-Pi network for COL1A1, COL1A2, COL3A1, and COL4A2 in human's cells and the interaction with UV, ROS, Pollution (Diesel Particulate Matter), and Skin Microbiome. ${ }^{184-186}$ A minimum number of three publications supporting the $\mathrm{Pi}-\mathrm{Pi}$ interaction was used as a confidence value; relationships with number of publications less than three were excluded. A preliminary network (Mammal's cells) was compared with the Human Protein Atlas Database ${ }^{180}$ to identify the protein expressed in the skin tissue. Protein results not expressed in the human skin tissue were discarded. The final components of the protein-protein network including 41 nodes and their relative interactions were charged in Cytoscape 3.7.1.

\section{Six Months' Clinical Study Data with Four Steps Regimen}

Twenty female volunteers aged $30-50$ years were recruited from the Bray area in Ireland. Prior to baseline measurements, all volunteers went through a wash-out phase. After 20 minutes of acclimatization under controlled temperature and humidity $\left(21^{\circ} \mathrm{C} \pm 2^{\circ} \mathrm{C}\right.$, relative humidity $50 \%$ $\pm 5 \%$ ), volunteers went through a set of wrinkle depth measurement with the Antera 3D (Miravex) at baseline, 1 month, 2 months, and 6 months later. Ethical approval was granted by the Oriflame R\&D Ethics Committee (Bray, Ireland). All study procedures were explained in detail, and written informed consent was obtained from all volunteers. The study was conducted in conformance with the most recent recommendations of the World Medical Association (Declaration of Helsinki 1964, amended in Fortaleza, Brazil, 2013). Repeated measures ANOVA with Dunnett post-hoc was computed to establish significant differences from baseline. The raw data (wrinkles depth) collected as part of this clinical study are available in Supplementary appendix 1A.

\section{Disclosure}

The authors report no conflicts of interest in this work.

\section{References}

1. Farage MA, Miller KW, Elsner P, Maibach HI. Characteristics of the aging skin. $A d v$ Wound Care. 2013;2(1):5-10. doi:10.1089/ wound.2011.0356

2. Gupta MA, Gilchrest BA. Psychosocial aspects of aging skin. Dermatol Clin. 2005;23(4):643-648. doi:10.1016/j.det.2005.05.012

3. Trojahn C, Dobos G, Lichterfeld A, Blume-Peytavi U, Kottner J. Characterizing facial skin ageing in humans: disentangling extrinsic from intrinsic biological phenomena. Biomed Res Int. 2015;2015:318586. doi:10.1155/2015/318586

4. Dong J, Lanoue J, Goldenberg G. Enlarged facial pores: an update on treatments. Cutis. 2016;98(1):33-36...

5. Wild CP. Complementing the genome with an "exposome": the outstanding challenge of environmental exposure measurement in molecular epidemiology. Cancer Epidemiol Biomarkers Prev. 2005;14 (8):1847-1850. doi:10.1158/1055-9965.EPI-05-0456

6. Miller GW, Jones DP. The nature of nurture: refining the definition of the exposome. Toxicol Sci. 2014;137(1):1-2. doi:10.1093/toxsci/kft251

7. Krutmann J, Bouloc A, Sore G, Bernard BA, Passeron T. The skin aging exposome. J Dermatol Sci. 2017;85(3):152-161. doi:10.1016/j. jdermsci.2016.09.015 
8. Rappaport SM. Genetic factors are not the major causes of chronic diseases. Scott RJed. PLoS One. 2016;11(4):e0154387. doi:10.1371/journal.pone. 0154387

9. Leffers HCB, Lange T, Collins C, Ulff-Møller CJ, Jacobsen S. The study of interactions between genome and exposome in the development of systemic lupus erythematosus. Autoimmun Rev. 2019;18(4):382-392. doi:10.1016/j.autrev.2018.11.005

10. Valdes AM, Walter J, Segal E, Spector TD. Role of the gut microbiota in nutrition and health. BMJ. 2018;361:k2179. doi:10.1136/bmj.k2179

11. The Human Microbiome Project Consortium. Structure, function and diversity of the healthy human microbiome. Nature. 2012;486 (7402):207-214. doi:10.1038/nature11234

12. Johnson T, Gómez B, McIntyre M, et al. The cutaneous microbiome and wounds: new molecular targets to promote wound healing. Int $J$ Mol Sci. 2018;19(9):2699. doi:10.3390/ ijms 19092699

13. Kim H-J, Kim JJ, Myeong NR, et al. Segregation of age-related skin microbiome characteristics by functionality. Sci Rep. 2019;9 (1):16748. doi:10.1038/s41598-019-53266-3

14. Jugé $\mathrm{R}$, Rouaud-Tinguely $\mathrm{P}$, Breugnot $\mathrm{J}$, et al. Shift in skin microbiota of Western European women across aging. $J$ Appl Microbiol. 2018;125(3):907-916. doi:10.1111/jam.13929

15. Ellis SR, Nguyen M, Vaughn AR, et al. The skin and gut microbiome and its role in common dermatologic conditions. Microorganisms. 2019;7(11):550. doi:10.3390/microorganisms 7110550

16. Grice EA, Segre JA. The skin microbiome. Nat Rev Microbiol. 2011;9(4):244-253. doi:10.1038/nrmicro2537

17. Salem I, Ramser A, Isham N, Ghannoum MA. The gut microbiome as a major regulator of the gut-skin axis. Front Microbiol. 2018;9:1459. doi:10.3389/fmicb.2018.01459

18. Bosman ES, Albert AY, Lui H, Dutz JP, Vallance BA. Skin exposure to narrow band ultraviolet (UVB) light modulates the human intestinal microbiome. Front Microbiol. 2019;10:2410. doi:10.3389/fmicb.2019.02410

19. Del Bino S, Duval C, Bernerd F. Clinical and biological characterization of skin pigmentation diversity and its consequences on UV impact. Int J Mol Sci. 2018;19(9):2668. doi:10.3390/ ijms 19092668

20. Sugiyama-Nakagiri Y, Sugata K, Hachiya A, Osanai O, Ohuchi A, Kitahara T. Ethnic differences in the structural properties of facial skin. $J$ Dermatol Sci. 2009;53(2):135-139. doi:10.1016/j.jdermsci.2008.08.008

21. Lee SJ, Seok J, Jeong SY, Park KY, Li K, Seo SJ. Facial pores: definition, causes, and treatment options. Dermatologic Surg. 2016;42(3):277-285. doi:10.1097/DSS.0000000000000657

22. Nouveau-Richard S, Yang Z, Mac-Mary S, et al. Skin ageing: A comparison between Chinese and European populations. J Dermatol Sci. 2005;40(3):187-193. doi:10.1016/j. jdermsci.2005.06.006

23. Montagna W, Carlisle K. The architecture of black and white facial skin. J Am Acad Dermatol. 1991;24(6 Pt 1):929-937. doi:10.1016/0190-9622(91)70148-u

24. Vashi NA, de Castro Maymone MB, Kundu RV. Aging differences in ethnic skin. J Clin Aesthet Dermatol. 2016;9(1):31-38.:.

25. Berardesca E, de Rigal J, Leveque JL, Maibach HI. In vivo biophysical characterization of skin physiological differences in races. Dermatology. 1991;182(2):89-93. doi:10.1159/000247752

26. Fantasia J, Lin CB, Wiwi C, et al. Differential levels of elastin fibers and TGF- $\beta$ signaling in the skin of Caucasians and African Americans. J Dermatol Sci. 2013;70(3):159-165. doi:10.1016/j. jdermsci.2013.03.004

27. Galzote C, Estanislao R, Suero MO, et al. Characterization of facial skin of various Asian populations through visual and non-invasive instrumental evaluations: influence of seasons. Ski Res Technol. 2014;20(4):453-462. doi:10.1111/srt.12140
28. Couturaud V, Coutable J, Khaiat A. Skin biomechanical properties: in vivo evaluation of influence of age and body site by a non-invasive method. Ski Res Technol. 1995;1(2):68-73. doi:10.1111/j.1600-0846.1995.tb00020.x

29. Alaluf S, Heath A, Carter N, et al. Variation in melanin content and composition in type $\mathrm{v}$ and vi photoexposed and photoprotected human skin: the dominant role of DHI. Pigment Cell Res. 2001;14(5):337-347. doi:10.1034/j.1600-0749.2001.140505.x

30. Kaidbey KH, Agin PP, Sayre RM, Kligman AM. Photoprotection by melanin-a comparison of black and Caucasian skin. $J \mathrm{Am}$ Acad Dermatol. 1979;1(3):249-260. doi:10.1016/s01909622(79)70018-1

31. Hillebrand GG, Miyamoto K, Schnell B, Ichihashi M, Shinkura R, Akiba S. Quantitative evaluation of skin condition in an epidemiological survey of females living in northern versus southern Japan. J Dermatol Sci. 2001;27(Suppl 1):S42-52. doi:10.1016/s0923-1811(01)00118-9

32. Murase D, Hachiya A, Takano K, et al. Autophagy has a significant role in determining skin color by regulating melanosome degradation in keratinocytes. J Invest Dermatol. 2013;133 (10):2416-2424. doi:10.1038/jid.2013.165

33. Halder RM, Richards GM. Topical agents used in the management of hyperpigmentation. Skin Therapy Lett. 9(6):1-3.

34. de Rigal J, Des Mazis I, Diridollou S, et al. The effect of age on skin color and color heterogeneity in four ethnic groups. Ski Res Technol. 2010;16(2):168-178. doi:10.1111/j.16000846.2009.00416.x

35. Voegeli R, Rawlings AV, Seroul P, Summers B. A novel continuous colour mapping approach for visualization of facial skin hydration and transepidermal water loss for four ethnic groups. Int J Cosmet Sci. 2015;37(6):595-605. doi:10.1111/ics.12265

36. Yamashita Y, Okano Y, Ngo T, et al. Differences in susceptibility to oxidative stress in the skin of japanese and french subjects and physiological characteristics of their skin. Skin Pharmacol Physiol. 2012;25(2):78-85. doi:10.1159/000335259

37. Makrantonaki E, Brink TC, Zampeli V, et al. Identification of biomarkers of human skin ageing in both genders. wnt signalling - a label of skin ageing? PLoS One. 2012;7(11):e50393. doi:10.1371/journal.pone.0050393

38. Seidenari S, Pagnoni A, Di Nardo AD, Giannetti A. Echographic evaluation with image analysis of normal skin: variations according to age and sex. Skin Pharmacol Physiol. 1994;7(4):201-209. doi:10.1159/000211295

39. Makrantonaki E, Bekou V, Zouboulis CC. Genetics and skin aging. Dermatoendocrinol. 2012;4(3):280-284. doi:10.4161/ derm. 22372

40. Pelle E, Jian J, Zhang Q, et al. Menopause increases the iron storage protein ferritin in skin. J Cosmet Sci. 64(3):175-179.:.

41. Brincat M, Kabalan S, Studd JW, Moniz CF, de Trafford J, Montgomery J. A study of the decrease of skin collagen content, skin thickness, and bone mass in the postmenopausal woman. Obstet Gynecol. 1987;70(6):840-845.:

42. Stevenson S, Nelson LD, Sharpe DT, Thornton MJ. 17ß-Estradiol regulates the secretion of TGF- $\beta$ by cultured human dermal fibroblasts. J Biomater Sci Polym Ed. 2008;19(8):1097-1109. doi:10.1163/156856208784909354

43. Moraes AB, Haidar MA, Soares JM, Simões MJ, Baracat EC, Patriarca MT. The effects of topical isoflavones on postmenopausal skin: double-blind and randomized clinical trial of efficacy. Eur J Obstet Gynecol Reprod Biol. 2009;146(2):188-192. doi:10.1016/j.ejogrb.2009.04.007

44. Maheux R, Naud F, Rioux M, et al. A randomized, double-blind, placebo-controlled study on the effect of conjugated estrogens on skin thickness. Am J Obstet Gynecol. 1994;170(2):642-649. doi:10.1016/s0002-9378(94)70242-x 
45. Sauerbronn AV, Fonseca AM, Bagnoli VR, Saldiva PH, Pinotti JA. The effects of systemic hormonal replacement therapy on the skin of postmenopausal women. Int J Gynaecol Obstet. 2000;68(1):35-41. doi:10.1016/s0020-7292(99)00166-6

46. Sator P-G, Sator MO, Schmidt JB, et al. A prospective, randomized, double-blind, placebo-controlled study on the influence of a hormone replacement therapy on skin aging in postmenopausal women. Climacteric. 2007;10(4):320-334. doi:10.1080 13697130701444073

47. Sumino H, Ichikawa S, Abe M, Endo Y, Ishikawa O, Kurabayashi M. Effects of aging, menopause, and hormone replacement therapy on forearm skin elasticity in women. $J$ Am Geriatr Soc. 2004;52 (6):945-949. doi:10.1111/j.1532-5415.2004.52262.x

48. Dunn LB, Damesyn M, Moore AA, Reuben DB, Greendale GA. Does estrogen prevent skin aging? Results from the first national health and nutrition examination survey (NHANES I). Arch Dermatol. 1997;133 (3):339-342. doi:10.1001/archderm.133.3.339

49. Friedman O. Changes Associated with the Aging Face. Facial Plast Surg Clin North Am. 2005;13(3):371-380. doi:10.1016/j. fsc. 2005.04 .004

50. Flament F, Bazin R, Rubert S, Simonpietri V, Piot B, Laquieze B. Effect of the sun on visible clinical signs of aging in Caucasian skin. Clin Cosmet Investig Dermatol. 2013;6:221. doi:10.2147/ CCID.S44686

51. Tewari A, Grage MML, Harrison GI, Sarkany R, Young AR. UVA1 is skin deep: molecular and clinical implications. Photochem Photobiol Sci. 2013;12(1):95-103. doi:10.1039/ c2pp25323b

52. McDaniel DH, Mazur C, Wortzman MS, Nelson DB. Efficacy and tolerability of a double-conjugated retinoid cream vs $1.0 \%$ retinol cream or $0.025 \%$ tretinoin cream in subjects with mild to severe photoaging. $J$ Cosmet Dermatol. 2017;16(4):542-548. doi:10.1111/jocd.12381

53. Hussein MR. Ultraviolet radiation and skin cancer: molecular mechanisms. J Cutan Pathol. 2005;32(3):191-205. doi:10.1111/ j.0303-6987.2005.00281.x

54. Cortat B, Garcia CCM, Quinet A, Schuch AP, de Lima-bessa KM, Menck CFM. The relative roles of DNA damage induced by UVA irradiation in human cells. Photochem Photobiol Sci. 2013;12 (8):1483. doi:10.1039/c3pp50023c

55. Ou-Yang H, Stamatas G, Saliou C, Kollias N. A chemiluminescence study of UVA-induced oxidative stress in human skin in vivo. J Invest Dermatol. 2004;122(4):1020-1029. doi:10.1111/j.0022-202X.2004.22405.x

56. Battie C, Jitsukawa S, Bernerd F, Del Bino S, Marionnet C, Verschoore M. New insights in photoaging, UVA induced damage and skin types. Exp Dermatol. 2014;23:7-12. doi:10.1111/ exd. 12388

57. Bernerd F, Asselineau D. UVA exposure of human skin reconstructed in vitro induces apoptosis of dermal fibroblasts: subsequent connective tissue repair and implications in photoaging. Cell Death Differ. 1998;5(9):792-802. doi:10.1038/sj. cdd. 4400413

58. Bernerd F, Asselineau D. Successive alteration and recovery of epidermal differentiation and morphogenesis after specific UVB-damages in skin reconstructed in vitro. Dev Biol. 1997;183(2):123-138. doi:10.1006/dbio.1996.8465

59. Scharffetter K, Wlaschek M, Hogg A, et al. UVA irradiation induces collagenase in human dermal fibroblasts in vitro and in vivo. Arch Dermatol Res. 1991;283(8):506-511. doi:10.1007/ bf00371923

60. Wlaschek M, Bolsen K, Herrmann G, et al. UVA-induced autocrine stimulation of fibroblast-derived-collagenase by il-6: a possible mechanism in dermal photodamage? $J$ Invest Dermatol. 1993;101(2):164-168. doi:10.1111/1523-1747. ep12363644
61. Marionnet C, Grether-Beck S, Seité S, et al. A broad-spectrum sunscreen prevents UVA radiation-induced gene expression in reconstructed skin in vitro and in human skin in vivo. Exp Dermatol. 2011;20(6):477-482. doi:10.1111/j.16000625.2011.01265.x

62. Marionnet C, Lejeune F, Pierrard C, Vioux-Chagnoleau C, Bernerd F. Biological contribution of UVA wavelengths in non extreme daily UV exposure. J Dermatol Sci. 2012;66(3):238-240. doi:10.1016/j.jdermsci.2012.02.018

63. Mera SL, Lovell CR, Jones RR, Davies JD. Elastic fibres in normal and sun-damaged skin: an immunohistochemical study. Br J Dermatol. 1987;117(1):21-27. doi:10.1111/j.13652133.1987.tb04086.x

64. Albrecht S, From L, Kahn HJ. Lysozyme in abnormal dermal elastic fibers of cutaneous aging, solar elastosis and pseudoxanthoma elasticum. $J$ Cutan Pathol. 1991;18(2):75-80. doi:10.1111/j.1600-0560.1991.tb00131.x

65. Park PW, Biedermann K, Mecham L, Bissett DL, Mecham RP. Lysozyme binds to elastin and protects elastin from elastase-mediated degradation. J Invest Dermatol. 1996;106 (5):1075-1080. doi:10.1111/1523-1747.ep12339292

66. Zhao P, Zhu X, Liu Y, Wang B, Wang C, Burns F. Solar ultraviolet radiation and skin damage: an epidemiological study among a chinese population. Arch Environ Heal an Int J. 1998;53(6):405-409. doi:10.1080/00039899809605728

67. Chung JH. Photoaging in Asians. Photodermatol Photoimmunol Photomed. 2003;19(3):109-121. doi:10.1034/j.16000781.2003.00027.x

68. Gilchrest BA, Park H-Y, Eller MS, Yaar M. Mechanisms of ultraviolet light-induced pigmentation. Photochem Photobiol. 1996;63(1):1-10. doi:10.1111/j.1751-1097.1996.tb02988.x

69. Pinnell SR. Cutaneous photodamage, oxidative stress, and topical antioxidant protection. J Am Acad Dermatol. 2003;48(1):1-22. doi:10.1067/mjd.2003.16

70. Olsen CM, Wilson LF, Green AC, Biswas N, Loyalka J, Whiteman DC. Prevention of DNA damage in human skin by topical sunscreens. Photodermatol Photoimmunol Photomed. 2017;33(3):135-142. doi:10.1111/phpp.12298

71. Franceschi C, BONAFÈ M, Valensin S, et al. Inflamm-aging: an evolutionary perspective on immunosenescence. Ann N Y Acad Sci. 2006;908(1):244-254. doi:10.1111/j.1749-6632.2000.tb06651.x

72. Marionnet C, Nouveau S, Hourblin V, et al. UVA1-induced skin darkening is associated with molecular changes even in highly pigmented skin individuals. $J$ Invest Dermatol. 2017;137 (5):1184-1187. doi:10.1016/j.jid.2016.12.016

73. Zhuang Y, Lyga J. Inflammaging in skin and other tissues - the roles of complement system and macrophage. Inflamm AllergyDrug Targets. 2014;13(3):153-161. doi:10.2174/ 1871528113666140522112003

74. Cho S, Lee MJ, Kim MS, et al. Infrared plus visible light and heat from natural sunlight participate in the expression of MMPs and type I procollagen as well as infiltration of inflammatory cell in human skin in vivo. J Dermatol Sci. 2008;50(2):123-133. doi:10.1016/j.jdermsci.2007.11.009

75. Dong K, Goyarts EC, Pelle E, Trivero J, Pernodet N. Blue light disrupts the circadian rhythm and create damage in skin cells. Int J Cosmet Sci. 2019;41(6):558-562. doi:10.1111/ics.12572

76. Cho S, Shin MH, Kim YK, et al. Effects of infrared radiation and heat on human skin aging in vivo. J Investig Dermatology Symp Proc. 2009;14(1):15-19. doi:10.1038/JIDSYMP.2009.7

77. Schieke SM, Stege H, Kürten V, Grether-Beck S, Sies H, Krutmann J. Infrared-a radiation-induced matrix metalloproteinase 1 expression is mediated through extracellular signal-regulated kinase $1 / 2$ activation in human dermal fibroblasts. $J$ Invest Dermatol. 2002;119(6):1323-1329. doi:10.1046/J.1523-1747.2002.19630.X 
78. Ghorani-Azam A, Riahi-Zanjani B, Balali-Mood M. Effects of air pollution on human health and practical measures for prevention in Iran. J Res Med Sci. 2016;21(1):65. doi:10.4103/1735-1995.189646

79. Brugha R, Grigg J. Urban air pollution and respiratory infections. Paediatr Respir Rev. 2014;15(2):194-199. doi:10.1016/j. prrv.2014.03.001

80. Flament F, Bourokba N, Nouveau S, Li J, Charbonneau A. A severe chronic outdoor urban pollution alters some facial aging signs in Chinese women. A tale of two cities. Int J Cosmet Sci. 2018;40(5):467-481. doi:10.1111/ics.12487

81. Makino ET, Jain A, Tan P, et al. Clinical efficacy of a novel two-part skincare system on pollution-induced skin damage. J Drugs Dermatol. 2018;17(9):975-981.:

82. Roberts WE. Pollution as a risk factor for the development of melasma and other skin disorders of facial hyperpigmentation - is there a case to be made? J Drugs Dermatol. 2015;14(4):337-341.:

83. Li M, Vierkötter A, Schikowski T, et al. Epidemiological evidence that indoor air pollution from cooking with solid fuels accelerates skin aging in Chinese women. J Dermatol Sci. 2015;79(2):148-154. doi:10.1016/j.jdermsci.2015.04.001

84. Lefebvre M-A, Pham D-M, Boussouira B, Bernard D, Camus C, Nguyen Q-L. Evaluation of the impact of urban pollution on the quality of skin: a multicentre study in Mexico. Int J Cosmet Sci. 2015;37(3):329-338. doi:10.1111/ics. 12203

85. Kim KE, Cho D, Park HJ. Air pollution and skin diseases: adverse effects of airborne particulate matter on various skin diseases. Life Sci. 2016;152:126-134. doi:10.1016/j.lfs.2016.03.039

86. Lotfi RA, El Zawahry KM, Kamar ZA, Hashem Z. Effects of smoking on human telomerase reverse transcriptase expression in the skin. Int J Dermatol. 2014;53(10):1205-1212. doi:10.1111/ ijd. 12467

87. Rossi M, Pistelli F, Pesce M, et al. Impact of long-term exposure to cigarette smoking on skin microvascular function. Microvasc Res. 2014;93:46-51. doi:10.1016/j.mvr.2014.03.001

88. Fan G-B, Wu P-L, Wang X-M. Changes of oxygen content in facial skin before and after cigarette smoking. Ski Res Technol. 2012;18(4):511-515. doi:10.1111/j.1600-0846.2011.00583.x

89. Leonardi-Bee J, Ellison T, Bath-Hextall F. Smoking and the risk of nonmelanoma skin cancer. Arch Dermatol. 2012;148 (8):939-946. doi:10.1001/archdermatol.2012.1374

90. Rollison DE, Iannacone MR, Messina JL, et al. Case-control study of smoking and non-melanoma skin cancer. Cancer Causes Control. 2012;23(2):245-254. doi:10.1007/s10552-011-9872-y

91. Engebretsen KA, Johansen JD, Kezic S, Linneberg A, Thyssen JP. The effect of environmental humidity and temperature on skin barrier function and dermatitis. J Eur Acad Dermatology Venereol. 2016;30(2):223-249. doi:10.1111/jdv.13301

92. Qiu H, Long X, Ye JC, et al. Influence of season on some skin properties: winter vs. summer, as experienced by 354 Shanghaiese women of various ages. Int J Cosmet Sci. 2011;33 (4):377-383. doi:10.1111/j.1468-2494.2011.00639.x

93. Nam GW, Baek JH, Koh JS, Hwang J-K. The seasonal variation in skin hydration, sebum, scaliness, brightness and elasticity in Korean females. Ski Res Technol. 2015;21(1):1-8. doi:10.1111/ srt.12145

94. Balato N, Ayala F, Megna M, Balato A, Patruno C. Climate change and skin. G Ital Dermatol Venereol. 2013;148 (1):135-146.:

95. Denda M, Sato J, Masuda Y, et al. Exposure to a dry environment enhances epidermal permeability barrier function. $J$ Invest Dermatol. 1998;111(5):858-863. doi:10.1046/j.15231747.1998.00333.x

96. Ashida Y, Ogo M, Denda M. Epidermal interleukin-1alpha generation is amplified at low humidity: implications for the pathogenesis of inflammatory dermatoses. Br J Dermatol. 2001;144 (2):238-243. doi:10.1046/j.1365-2133.2001.04007.x
97. Singh B, Maibach H. Climate and skin function: an overview. Ski Res Technol. 2013;19(3):207-212. doi:10.1111/srt.12043

98. Youn SW, Na JI, Choi SY, Huh CH, Park KC. Regional and seasonal variations in facial sebum secretions: a proposal for the definition of combination skin type. Ski Res Technol. 2005;11 (3):189-195. doi:10.1111/j.1600-0846.2005.00119.x

99. Egawa M, Oguri M, Kuwahara T, Takahashi M. Effect of exposure of human skin to a dry environment. Ski Res Technol. 2002;8 (4):212-218. doi:10.1034/j.1600-0846.2002.00351.x

100. Oyetakin-White P, Suggs A, Koo B, et al. Does poor sleep quality affect skin ageing? Clin Exp Dermatol. 2015;40(1):17-22. doi:10.1111/ced.12455

101. Kim MA, Kim EJ, Kang BY, Lee HK. The effects of sleep deprivation on the biophysical properties of facial skin. $J$ Cosmet Dermatological Sci Appl. 2017;07(01):34-47. doi:10.4236/jcdsa.2017.71004

102. Kleszczynski K, Fischer TW. Melatonin and human skin aging. Dermatoendocrinol. 2012;4(3):245-252. doi:10.4161/derm.22344

103. Rusanova I, Martínez-Ruiz L, Florido J, et al. Protective effects of melatonin on the skin: future perspectives. Int $J$ Mol Sci. 2019;20:19. doi:10.3390/ijms20194948

104. Trinity JD, Broxterman RM, Richardson RS. Regulation of exercise blood flow: role of free radicals. Free Radic Biol Med. 2016;98:90-102. doi:10.1016/j.freeradbiomed.2016.01.017

105. Bugaj O, Zieliński J, Kusy K, Kantanista A, Wieliński D, Guzik P. The effect of exercise on the skin content of the reduced form of nad and its response to transient ischemia and reperfusion in highly trained athletes. Front Physiol. 2019;10:600. doi:10.3389/fphys.2019.00600

106. Shiohara T, Sato Y, Komatsu Y, Ushigome Y, Mizukawa Y. Sweat as an efficient natural moisturizer. Curr Probl Dermatol. 2016;51:30-41. doi:10.1159/000446756

107. Wang S, Zhang G, Meng H, Li L. Effect of Exercise-induced Sweating on facial sebum, stratum corneum hydration, and skin surface pH in normal population. Ski Res Technol. 2013;19(1): e312-e317. doi:10.1111/j.1600-0846.2012.00645.x

108. Crane JD, MacNeil LG, Lally JS, et al. Exercise-stimulated interleukin- 15 is controlled by AMPK and regulates skin metabolism and aging. Aging Cell. 2015;14(4):625-634. doi:10.1111/acel.12341

109. Garatachea N, Pareja-Galeano H, Sanchis-Gomar F, et al. Exercise attenuates the major hallmarks of aging. Rejuvenation Res. 2015;18(1):57-89. doi:10.1089/rej.2014.1623

110. Kurtz ES, Wallo W. Colloidal oatmeal: history, chemistry and clinical properties. J Drugs Dermatol. 2007;6(2):167-170.:

111. Schagen SK, Zampeli VA, Makrantonaki E, Zouboulis CC. Discovering the link between nutrition and skin aging. Dermatoendocrinol. 2012;4(3):298-307. doi:10.4161/derm.22876

112. Shah MMR, Liang Y, Cheng JJ, Daroch M. Astaxanthinproducing green microalga haematococcus pluvialis: from single cell to high value commercial products. Front Plant Sci. 2016;7:531. doi:10.3389/fpls.2016.00531

113. Davinelli S, Nielsen M, Scapagnini G. Astaxanthin in skin health, repair, and disease: a comprehensive review. Nutrients. 2018;10 (4):522. doi:10.3390/nu10040522

114. Vollmer D, West V, Lephart E. Enhancing skin health: by oral administration of natural compounds and minerals with implications to the dermal microbiome. Int J Mol Sci. 2018;19(10):3059. doi:10.3390/ijms 19103059

115. Cipolletti M, Solar Fernandez V, Montalesi E, Marino M, Fiocchetti M. Beyond the antioxidant activity of dietary polyphenols in cancer: the modulation of estrogen receptors (ers) signaling. Int J Mol Sci. 2018;19(9):2624. doi:10.3390/ijms19092624

116. Działo M, Mierziak J, Korzun U, Preisner M, Szopa J, Kulma A. The potential of plant phenolics in prevention and therapy of skin disorders. Int $J$ Mol Sci. 2016;17(2):160. doi:10.3390/ ijms 17020160 
117. Nwanodi O. Skin protective nutraceuticals: the current evidence in brief. Healthcare. 2018;6(2):40. doi:10.3390/healthcare6020040

118. Tessema EN, Gebre-Mariam T, Neubert RHH, Wohlrab J. Potential applications of phyto-derived ceramides in improving epidermal barrier function. Skin Pharmacol Physiol. 2017;30 (3):115-138. doi:10.1159/000464337

119. Bizot V, Cestone E, Michelotti A, Nobile V. Improving skin hydration and age-related symptoms by oral administration of wheat glucosylceramides and digalactosyl diglycerides: a human clinical study. Cosmetics. 2017;4(4):37. doi:10.3390/cosmetics4040037

120. Balić A, Vlašić D, Žužul K, Marinović B, Bukvić Mokos Z. Omega-3 versus omega- 6 polyunsaturated fatty acids in the prevention and treatment of inflammatory skin diseases. Int $J \mathrm{Mol}$ Sci. 2020;21(3):741. doi:10.3390/ijms21030741

121. Fink B, Matts P. The effects of skin colour distribution and topography cues on the perception of female facial age and health. J Eur Acad Dermatology Venereol. 2008;22(4):493-498. doi:10.1111/j.1468-3083.2007.02512.x

122. Messaraa C. The eyes of others is it of interest for the cosmetic industry? In-cosmetic 2019 workshops and seminars, podium presentation; 2019.

123. Messaraa C, Richard T, Walsh M, et al.Perceived age and perceived health among a Chinese cohort: does it mean the same thing? Int J Cosmt Sci.2020;42:471-481. doi:10.1111/ics.12647

124. O'Connor C, Messaraa C, Kearney EM, Robertson N. Clinical confirmation: multi-step routines deliver better benefits to skin. Cosmet Toilet. 2020;135:39-43.

125. Bedos P, Leduc C, Damez C, Sirvent AGFALK. Anti-aging benefits. beyond wrinkle reduction. Cosmet Toilet. 2016;131 (23-34).

126. Ye L, Mauro TM, Dang E, et al. Topical applications of an emollient reduce circulating pro-inflammatory cytokine levels in chronically aged humans: a pilot clinical study. J Eur Acad Dermatology Venereol. 2019;33(11):2197-2201. doi:10.1111/ jdv. 15540

127. Man M-Q, Elias PM. Could inflammaging and its sequelae be prevented or mitigated? Clin Interv Aging. 2019;14:2301-2304. doi:10.2147/CIA.S235595

128. Peters EMJ. Stressed skin? - a molecular psychosomatic update on stress-causes and effects in dermatologic diseases. JDDG J der Dtsch Dermatologischen Gesellschaft. 2016;14(3):233-252. doi:10.1111/ddg.12957

129. Fukuda S, Baba S, Akasaka T. Psychological stress has the potential to cause a decline in the epidermal permeability barrier function of the horny layer. Int J Cosmet Sci. 2015;37(1):63-69. doi:10.1111/ics. 12169

130. Bin Saif G, Alotaibi H, Alzolibani A, et al. Association of psychological stress with skin symptoms among medical students. Saudi Med J. 2018;39(1):59-66. doi:10.15537/ smj.2018.1.21231

131. Meštrović-Štefekov J, Novak-Bilić G, Kuna M, Pap N, LugovićMihić L. Psychological stress in patients with atopic dermatitis. Acta Dermatovenerol Croat. 2018;26(4):297-303.

132. O’Neill CA, Monteleone G, McLaughlin JT, Paus R. The gut-skin axis in health and disease: A paradigm with therapeutic implications. BioEssays. 2016;38(11):1167-1176. doi:10.1002/ bies. 201600008

133. Brandwein M, Katz I, Katz A, Kohen R. Beyond the gut: skin microbiome compositional changes are associated with BMI. Hum Microb J. 2019;13:100063. doi:10.1016/j.humic.2019 .100063

134. Ishii Y, Sugimoto S, Izawa N, Sone T, Chiba K, Miyazaki K. Oral administration of Bifidobacterium breve attenuates UV-induced barrier perturbation and oxidative stress in hairless mice skin. Arch Dermatol Res. 2014;306(5):467-473. doi:10.1007/s00403014-1441-2
135. Kim HM, Lee DE, Park SD, et al. Oral administration of lactobacillus plantarum hy7714 protects hairless mouse against ultraviolet b-induced photoaging. J Microbiol Biotechnol. 2014;24 (11):1583-1591. doi:10.4014/jmb.1406.06038

136. Lee DE, Huh C-S, Ra J, et al. Clinical evidence of effects of lactobacillus plantarum hy7714 on skin aging: a randomized, double blind, placebo-controlled study. J Microbiol Biotechnol. 2015;25(12):2160-2168. doi:10.4014/jmb.1509.09021

137. Jeong -J-J, Kim KA, Hwang Y-J, Han MJ, Kim D-H. Antiinflammaging effects of Lactobacillus brevis OW38 in aged mice. Benef Microbes. 2016;7(5):707-718. doi:10.3920/ BM2016.0016

138. Stokes JH, Pillsbury DM. The effect on the skin of emotional and nervous states: iii. theoretical and practical consideration of a gastro-intestinal mechanism. Arch Derm Syphilol. 1930;22 (6):962-993. doi:10.1001/ARCHDERM.1930.01440180008002

139. Bowe WP, Logan AC. Acne vulgaris, probiotics and the gut-brain-skin axis - back to the future? Gut Pathog. 2011;3 (1):1. doi:10.1186/1757-4749-3-1

140. Tsoucaris G, Martinetto P, Walter P, Lévêque JL. [Chemistry of cosmetics in antiquity]. Ann Pharm Fr. 2001;59(6):415-422. French.

141. Shanbhag S, Nayak A, Narayan R, Nayak UY. Anti-aging and sunscreens: paradigm shift in cosmetics. Adv Pharm Bull. 2019;9 (3):348-359. doi:10.15171/apb.2019.042

142. Lorencini M, Brohem CA, Dieamant GC, Zanchin NIT, Maibach HI. Active ingredients against human epidermal aging. Ageing Res Rev. 2014;15:100-115. doi:10.1016/j.arr.2014.03.002

143. Riahi RR, Bush AE, Cohen PR. Topical retinoids: therapeutic mechanisms in the treatment of photodamaged skin. Am J Clin Dermatol. 2016;17(3):265-276. doi:10.1007/s40257-016-0185-5

144. Lee C-M. Fifty years of research and development of cosmeceuticals: a contemporary review. J Cosmet Dermatol. 2016;15 (4):527-539. doi:10.1111/jocd.12261

145. Draelos ZD. Cosmeceuticals. Dermatol Clin. 2019;37 (1):107-115. doi:10.1016/j.det.2018.07.001

146. de Lima Cherubim DJ, Buzanello Martins CV, Oliveira Fariña L, da Silva de Lucca RA. Polyphenols as natural antioxidants in cosmetics applications. J Cosmet Dermatol. 2020;19(1):33-37. doi:10.1111/jocd.13093

147. Rodan K, Fields K, Falla TJ. Efficacy of a twice-daily, 3-step, over-the-counter skincare regimen for the treatment of acne vulgaris. Clin Cosmet Investig Dermatol. 2017;10:3-9. doi:10.2147/CCID.S125438

148. Chang ALS, Chen SC, Osterberg L, Brandt S, von Grote EC, Meckfessel $\mathrm{MH}$. A daily skincare regimen with a unique ceramide and filaggrin formulation rapidly improves chronic xerosis, pruritus, and quality of life in older adults. Geriatr Nurs. 2018;39 (1):24-28. doi:10.1016/j.gerinurse.2017.05.002

149. Messaraa C, Robertson N, Walsh M, et al. Clinical evidences of benefits from an advanced skin care routine in comparison with a simple routine. J Cosmet Dermatol. 2019. doi:10.1111/jocd.13252

150. Farage MA, Miller KW, Elsner P, Maibach HI. Functional and physiological characteristics of the aging skin. Aging Clin Exp Res. 2008;20(3):195-200. doi:10.1007/bf03324769

151. Wilhelm KP, Cua AB, Maibach HI. Skin aging. Effect on transepidermal water loss, stratum corneum hydration, skin surface $\mathrm{pH}$, and casual sebum content. Arch Dermatol. 1991;127 (12):1806-1809. doi:10.1001/archderm.127.12.1806

152. Pochi PE, Strauss JS, Downing DT. Age-related changes in sebaceous gland activity. $J$ Invest Dermatol. 1979;73 (1):108-111. doi:10.1111/1523-1747.ep12532792

153. Cotterill JA, Cunliffe WJ, Williamson B, Bulusu L. Age and sex variation in skin surface lipid composition and sebum excretion rate. $B r J$ Dermatol. 1972;87(4):333-340. doi:10.1111/j.13652133.1972.tb07419.x 
154. Somerville DA. The normal flora of the skin in different age groups. Br J Dermatol. 1969;81(4):248-258. doi:10.1111/j.13652133.1969.tb13976.x

155. Leyden JJ, McGinley KJ, Mills OH, Kligman AM. Propionibacterium levels in patients with and without acne vulgaris. J Invest Dermatol. 1975;65(4):382-384. doi:10.1111/ 1523-1747.ep12607634

156. Shibagaki N, Suda W, Clavaud C, et al. Aging-related changes in the diversity of women's skin microbiomes associated with oral bacteria. Sci Rep. 2017;7(1):10567. doi:10.1038/s41598-017-10834-9

157. Patra V, Wagner K, Arulampalam V, Wolf P. Skin microbiome modulates the effect of ultraviolet radiation on cellular response and immune function. iScience. 2019;15:211-222. doi:10.1016/j. isci.2019.04.026

158. Belkaid Y, Segre JA. Dialogue between skin microbiota and immunity. Science. 2014;(80-). doi:10.1126/science.1260144.

159. Lai Y, Di Nardo A, Nakatsuji T, et al. Commensal bacteria regulate Toll-like receptor 3-dependent inflammation after skin injury. Nat Med. 2009;15(12):1377-1382. doi:10.1038/nm.2062

160. Nakatsuji T, Chen TH, Butcher AM, et al. A commensal strain of Staphylococcus epidermidis protects against skin neoplasia. Sci Adv. 2018;4(2):eaao4502. doi:10.1126/sciadv.aao4502

161. Khmaladze I, Butler É, Fabre S, Gillbro JM. Lactobacillus reuteri DSM 17938-A comparative study on the effect of probiotics and lysates on human skin. Exp Dermatol. 2019;28(7):822-828. doi:10.1111/exd.13950

162. Meloni M, Balzaretti S, Carriero F, Ferrari R, Ceriotti L. New insights on skin responses to UV: the contribution of skin associated microbiome. IFSCC 2019, podium presentation; 2019.

163. Ashkenazi H, Malik Z, Harth Y, Nitzan Y. Eradication of Propionibacterium acnes by its endogenic porphyrins after illumination with high intensity blue light. FEMS Immunol Med Microbiol. 2003;35(1):17-24. doi:10.1111/j.1574-695X.2003.tb00644.x

164. Tsoukas M, Adya K, Inamadar A, Pei S. Light-based therapies in acne treatment. Indian Dermatol Online J. 2015;6(3):145. doi: $10.4103 / 2229-5178.156379$

165. Thiboutot D, Gollnick H, Bettoli V, et al. New insights into the management of acne: an update from the global alliance to improve outcomes in acne group. J Am Acad Dermatol. 2009;60 (5 Suppl):S1-50. doi:10.1016/j.jaad.2009.01.019

166. Wang Y, Wang Y, Wang Y, et al. Antimicrobial blue light inactivation of pathogenic microbes: state of the art. Drug Resist Updat. 2017;33-35:1-22. doi:10.1016/j.drup.2017.10.002

167. Dréno B, Bettoli V, Araviiskaia E, Sanchez Viera M, Bouloc A. The influence of exposome on acne. J Eur Acad Dermatol Venereol. 2018;32(5):812-819. doi:10.1111/jdv.14820

168. Krutmann J, Moyal D, Liu W, et al. Pollution and acne: is there a link? Clin Cosmet Investig Dermatol. 2017;10:199-204. doi: $10.2147 /$ CCID.S131323

169. Liu W, Pan X, Vierkötter A, et al. A time-series study of the effect of air pollution on outpatient visits for acne vulgaris in Beijing. Skin Pharmacol Physiol. 2018;31(2):107-113. doi:10.1159/000484482

170. Leung MHY, Tong X, Bastien P, et al. Changes of the human skin microbiota upon chronic exposure to polycyclic aromatic hydrocarbon pollutants. Microbiome. 2020;8:100. doi:10.1186/s40168020-00874-1
171. Borrel V, Thomas P, Catovic C, et al. Acne and stress: impact of catecholamines on cutibacterium acnes. Front Med. 2019;6:155. doi:10.3389/fmed.2019.00155

172. Yves Morvan P, Vallee R. Evaluation of the effects of stressful life on human skin microbiota. Appl Microbiol Open Access. 2018;04:01. doi:10.4172/2471-9315.1000140

173. Smith RP, Easson C, Lyle SM, et al. Gut microbiome diversity is associated with sleep physiology in humans. PLoS One. 2019;14 (10):e0222394. doi:10.1371/journal.pone.0222394

174. Andersson T, Ertürk Bergdahl G, Saleh K, et al. Common skin bacteria protect their host from oxidative stress through secreted antioxidant RoxP. Sci Rep. 2019;9(1):3596. doi:10.1038/s41598019-40471-3

175. Bouslimani A, da Silva R, Kosciolek T, et al. The impact of skin care products on skin chemistry and microbiome dynamics. BMC Biol. 2019;17(1):47. doi:10.1038/s12915-019-0660-6178

176. Staudinger T, Pipal A, Redl B. Molecular analysis of the prevalent microbiota of human male and female forehead skin compared to forearm skin and the influence of make-up. $J$ Appl Microbiol. 2011;110(6):1381-1389. doi:10.1111/j.13652672.2011.04991.x

177. Feng S, Zhou L, Huang C, Xie K, Nice EC. Interactomics: toward protein function and regulation. Expert Rev. 2014;1-24.

178. Kim S, Chen J, Cheng T, et al. PubChem 2019 update: improved access to chemical data. Nucleic Acids Res. 2019;47:D1. doi:10.1093/nar/gky1033

179. Hatcher EL, Zhdanov SA, Bao Y, et al. Virus Variation Resource - improved response to emergent viral outbreaks. Nucleic Acids Res. 2017;45(D1):D482-D490. doi:10.1093/nar/ gkw1065

180. Fagerberg L, Hallström BM, Lindskog C, et al. Tissue-based map of the human proteome. Science. 2015;347:6220.

181. Visdal-Johnsen L, Leonardi M, Österlund C, Fabre S, Sjölander E, Al-Bader T. Patent. 2018;WO2018185214.

182. Fabre S, Leonardi M; Solution Story: merging system biology \& chemistry to streamline the quest for natural active agents; https: www.elsevier.com/rd-solutions., 2018

183. Michele Leonardi M, Visdal-Johnsen L. Network Pharmacognosy as a new paradigm in the post-genomic era. Application to the development of a new anti-aging natural extract. Int J Phytocosmetics Natural Ingredients. 2017;S(05):50.

184. Sun J-L, Zhang S-K, Chen J-Y, Han B-Z. Metabolic profiling of Staphylococcus aureus cultivated under aerobic and anaerobic conditions with (1)H NMR-based nontargeted analysis. Can $J$ Microbiol. 2012;58(6):709-718. doi:10.1139/w2012-046

185. Tax G, Urbán E, Palotás Z, et al. Propionic Acid Produced by Propionibacterium acnes Strains Contri-butes to Their Pathogenicity. Acta Derm Venereol. 2016;96(1):43-49. doi:10.2340/00015555-2154

186. Filipiak W, Sponring A, Baur MM, et al. Molecular analysis of volatile metabolites released specifically by Staphylococcus aureus and Pseudomonas aeruginosa. BMC Microbiol. 2012;12:113. doi:10.1186/1471-2180-12-113
Clinical, Cosmetic and Investigational Dermatology is an international, peer-reviewed, open access, online journal that focuses on the latest clinical and experimental research in all aspects of skin disease and cosmetic interventions. This journal is indexed on CAS.
The manuscript management system is completely online and includes a very quick and fair peer-review system, which is all easy to use. Visit http://www.dovepress.com/testimonials.php to read real quotes from published authors. 